\title{
Long non-coding RNA and tumor hypoxia: new players ushered toward an old arena
}

\author{
Jing-Wen Shih ${ }^{1,2,3^{*}}$ (D) and Hsing-Jien Kung ${ }^{1,2,4,5}$
}

\begin{abstract}
Hypoxia is a classic feature of the tumor microenvironment with a profound impact on cancer progression and therapeutic response. Activation of complex hypoxia pathways orchestrated by the transcription factor HIF (hypoxia-inducible factor) contributes to aggressive phenotypes and metastasis in numerous cancers. Over the past few decades, exponentially growing research indicated the importance of the non-coding genome in hypoxic tumor regions. Recently, key roles of long non coding RNAs (IncRNAs) in hypoxia-driven cancer progression have begun to emerge. These hypoxia-responsive IncRNAs (HRLs) play pivotal roles in regulating hypoxic gene expression at chromatic, transcriptional, and post-transcriptional levels by acting as effectors of the indirect response to HIF or direct modulators of the HIF-transcriptional cascade. Notably, the aberrant expression of HRLs significantly correlates with poor outcomes in cancer patients, showing promise for future utility as a tumor marker or therapeutic target. Here we address the latest advances made toward understanding the functional relevance of $H R L s$, the involvement of these transcripts in hypoxia response and the underlying action mechanisms, highlighting their specific roles in HIF-1 signaling regulation and hypoxia-associated malignant transformation.
\end{abstract}

Keywords: Hypoxia, HIF-1a, Long non-coding RNA, IncRNA, Cancer, Hypoxia-responsive IncRNAs, HRL, Metastasis

\section{Background}

Tumor hypoxia: An old clinical arena

Maintenance of oxygen homeostasis underlies many critical developmental and physiological processes in mammalian cells. Consequently, to survive under physiological, oxygen deficient (or called hypoxia) conditions, cells have developed an essential and complex set of adaptive mechanisms including the up and down regulation of several hundred protein-coding genes [1]. Hypoxia can occur as a systematic low atmospheric oxygen level or locally at sites of inflammation, tissue ischemia and injury. Of note, hypoxic areas are common mircoenvironmental characteristics of rapidly growing tumors, and the fundamental adaptive responses are believed to be co-opted by cancer cells to promote many key aspects of cancer progression. Indeed, tumor hypoxia is associated with metastases, recurrences and resistance to therapy, and drives critical steps in oncogenic transformation, malignant progression

\footnotetext{
*Correspondence: shihjw@tmu.edu.tw

${ }^{1}$ Ph.D. Program for Cancer Biology and Drug Discovery, College of Medical Science and Technology, Taipei Medical University, Taipei 110, Taiwan

${ }^{2}$ Research Center of Cancer Translational Medicine, Taipei Medical University, Taipei 110, Taiwan

Full list of author information is available at the end of the article
}

and aggressive phenotype in many cancer types [2-4]. However, the molecular details leading to the hypoxic survival advantage of neoplastic cells have not been fully elucidated. Thus, a better understanding of hypoxic adaption is of critical importance to appreciate tumorigenesis process and to develop novel strategies for pharmacological intervention.

The cellular response to hypoxia insult is mainly governed by a family of transcription factors known as hypoxia inducible factors (HIFs), although HIF-independent responses also exist [5]. HIF is a heterodimer of bHLHPAS (basic helix-loop-helix DNA binding proteins of the PER-ARNT- - $I M$ family) proteins composed of an oxygenregulated $\alpha$ subunit and a constitutively expressed, stable $\beta$ subunit [6]. In mammals, the $\alpha$ subunits are encoded by three genes: HIF1A, HIF2A (also known as EPAS1, Endothelial PAS domain-containing protein 1) and HIF3A; whereas the HIF1 $\beta$ subunits (HIF1B; also known as ARNT, aryl hydrocarbon receptor nuclear translocators), are encoded by two genes ARNT1 and ARNT2. HIF-1 $\alpha$ and HIF- $2 \alpha$ regulate independent, but overlapping sets of transcriptional target genes, while certain splice variants of 
HIF-3 $\alpha$ exert dominant negative effects on HIFdependent gene transcription.

Under normoxic conditions, the HIF- $1 \alpha$ subunits are rapidly hydroxylated by a family of prolyl hydroxylase domain-containing (PHD1, 2 and 3, also known as Egl-9 family hypoxia inducible factor 1-3, EGLN1-3) dioxygenases, subsequently recognized by the VHL (von Hippel-Lindau tumor suppressor protein) E3 ubiquitin ligase complex, leading to the rapid degradation of HIF- $1 \alpha$ through the proteasome pathway (Fig. 1). Upon hypoxia, the dioxygenase PHD activity is inhibited, the HIF-1 $\alpha$ subunit is stabilized, accumulating in the nucleus, and forming a stable complex with the $\beta$ subunit. This complex binds DNA at specific sites containing the consensus nucleotide sequence $5^{\prime}$-(A/G)CGTG-3' within the hypoxia response elements (HREs) in the promoter regions of
HIF1 target genes to stimulate downstream transcription [7]. In particular, it was revealed that, in mammalian systems, HIF-1 can act as an activator or repressor in a cell context-specific manner, whereas the set of genes regulated by HIF-1 differs among cell types [8]. Collectively, hypoxia elicits highly coordinated HIF-dependent transcriptional activation evoking a broad range of cellular adaptions, such as metabolic rewiring, enhanced proliferation, decreased apoptosis, angiogenic growth, and can facilitate cell survival in this scenario [7, 9-11]. The activation of HIF-1 pathways is associated with an aggressive tumor phenotype and poor clinical outcome in numerous cancer types. Therefore, the exploration of the regulatory mechanism underlying HIF-1-mediated transcriptional control may lead to a better understanding of the contribution of hypoxia to tumor progression.

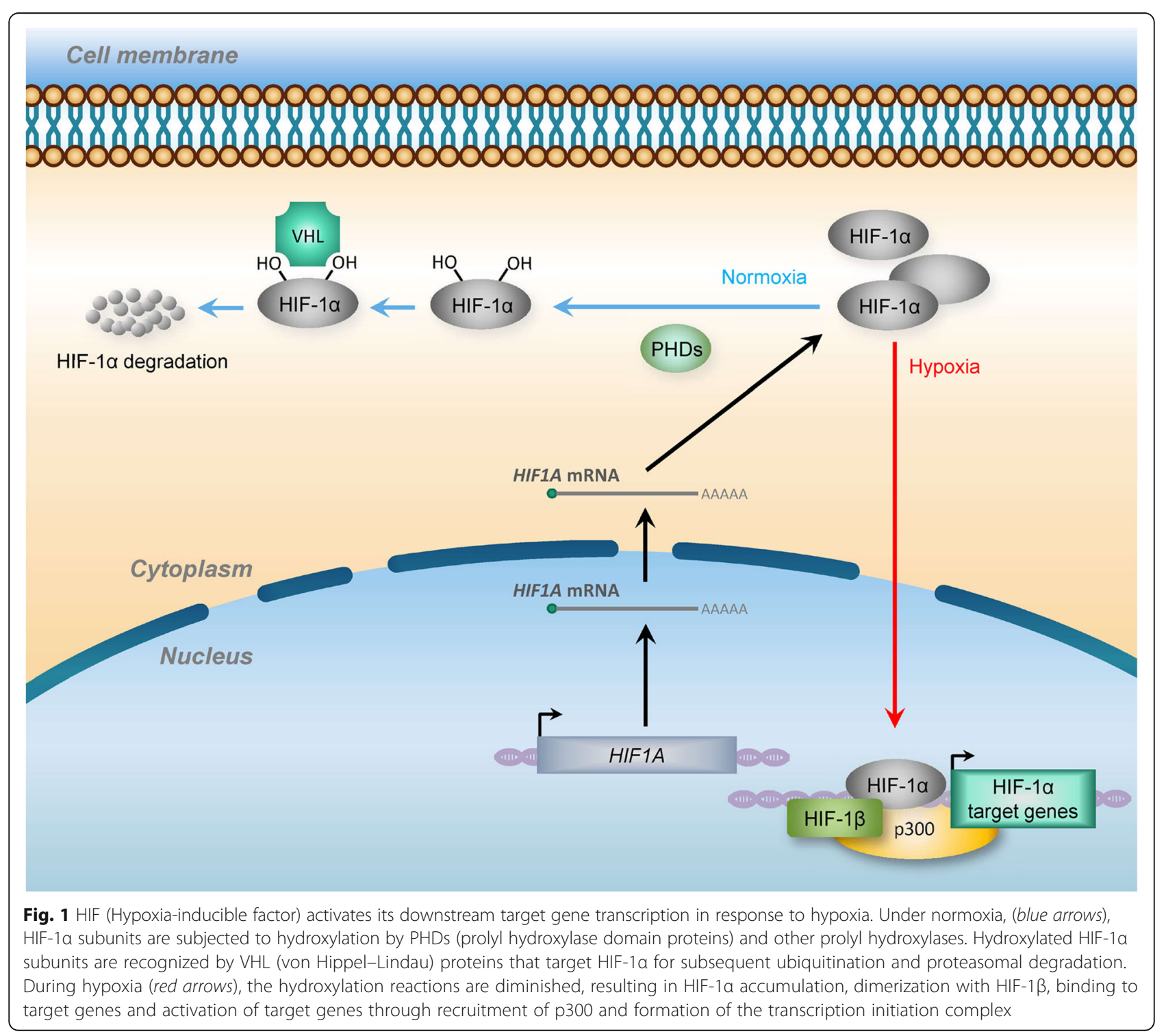


Long non-coding RNAs: New players in tumorigenesis In human genome, less than $2 \%$ of the DNA sequence is protein-coding, while up to $70 \%$ is transcribed into RNA $[12,13]$. Many of these transcribed, non-coding RNAs, once thought to represent transcriptional noise, has now been recognized as having important functions in cellular processes. By means of deep sequencing and bioinformatics, an astounding number of noncoding RNAs (ncRNAs) have been annotated in multiple model organisms, from yeast to humans [13-16].

Long non-coding RNAs (lncRNAs) are currently defined as a large and heterogeneous class of regulatory transcripts longer than 200 nucleotides lacking evident protein coding potential [14]. Encompassed within this broad category are different classes of transcribed elements, including long intergenic and intronic ncRNAs, transcribed ultra-conserved regions (TCRs), pseudogenes, enhancer RNAs (eRNAs) and antisense RNAs (asRNAs) [17]. Similar to protein-coding RNAs, the majority of lncRNAs are RNA polymerase II transcripts with a poly-A tail and $5^{\prime}$ cap. Interestingly, most lncRNAs are predominantly localized within the cell nucleus, and exhibit lower evolutionary conservation and lower expression level than mRNAs [14, 16, 18]. According to the GENCODE current release (http:// www.gencodegenes.org/stats/current.html) of the Ensembl human genome annotation (GRch38, version 26 from March 2017), 27,720 transcripts originating from 15,787 genes were identified as IncRNAs [19, 20]. Although less than $1 \%$ of the identified human lncRNAs have been functionally characterized, these lncRNAs participate in a variety of biological steps, such as chromosome dosagecompensation, imprinting, epigenetic regulation, cell cycle control, nuclear and cytoplasmic trafficking, transcription, translation, splicing and cell differentiation [21-25].

The distinctive biochemical properties of RNA endow these long non-coding RNA transcripts with multifunctionality [26, 27]. For instance, lncRNAs could achieve sequence-specific binding to other nucleic acids simply through one-to-one base pairing interactions, thereby influencing the activities and metabolism of target DNA or RNA. By folding into intricate three dimensional structures providing multifarious interacting surfaces, lncRNA can recognize various molecular targets with high affinity and specificity. In addition, the dynamic RNA expression and structure make lncRNAs well suited for rapid and transient fine-tuning of gene regulation. RNA is relatively flexible and hence provides an excellent platform for evolutionary innovation. More specifically, unrestricted by amino acid-coding potential contained within their sequences, regulatory RNAs are less constrained regarding their conservation. Virtually, RNAs are more tolerant of nucleotide mutations, allowing for the rapid evolution of diverse cellular functions. Most remarkably, as the information recorded within RNA transcripts can be integrated back into the genome through retroviral insertion, these RNA-dependent events could have the capacity to become heritable. Indeed, it has been shown that most lncRNAs exhibit weak primary sequence conservation and elicit functional outcomes through their interactions with cellular macromolecules, such as chromatin DNA, proteins and RNAs [26-30]. The rapidly expanding repertoire of lncRNA functions could be summarized as signals, decoys, guides and scaffolds [28, 30-34]. It is now well appreciated that lncRNA serves as an integral and crucial layer of biological regulation $[18,25,29$, 30].

The spatial- and temporal-specific expression patterns of many identified lncRNAs indicate that the expression of lncRNA is tightly regulated $[35,36]$. In recent years, with advancements in global transcriptome profiling, mounting amount of differentially expressed lncRNAs have been linked to various human diseases, most notably cancer [37-40]. To date, numerous cancerassociated lncRNAs are reported to modulate tumor growth, invasion and metastasis. However, only a handful of cancer-associated lncRNAs have been functionally characterized as tumor suppressors or oncogenic drivers in prevalent cancer types [30, 41]. Furthermore, aberrant expression of lncRNAs in cancer marks both clinicopathological features and patient outcomes in a range of cancers. Of note, due to their unique RNA properties, more tissue-specific expression fashion and more stable structure, it is expected that lncRNAs may potentially serve as attractive biomarkers for diagnosis and prognosis. Indeed, several lncRNAs have already been utilized in clinical practice [42]. Thus, knowledge about the functional roles of these aberrantly expressed lncRNAs in tumorigenesis may advance our understanding of cancer progression and unveiled novel diagnostic and therapeutic opportunities.

\section{New games: Interplay of hypoxia-responsive IncRNAs (HRLs) and HIF signaling in tumorigenesis}

Although the regulation of HIF-1 signaling and accompanied global transcriptional responses have been extensively characterized, the downstream and multifarious phenotypic changes associated with hypoxia are still in demand to be further elucidated. Over the last few years, a wealth of independent studies have demonstrated that expression of a specific group of lncRNA molecules are modulated by hypoxia [43-45]. Here, we denote these uniquely regulated long non-coding transcripts as "hypoxia responsive lncRNAs" (HRLs; Table 1 and Additional file 1: Table S1). These RNA molecules are involved in multiple tumorigenesis processes during the hypoxic 
Table 1 List of hypoxia-responsive IncRNAs

\begin{tabular}{|c|c|c|c|c|}
\hline IncRNA & Status upon hypoxia & HIF involvement & HRE location & References \\
\hline \multicolumn{5}{|l|}{ HIF-independent regulation } \\
\hline ATG9B (noncoding isoform) & Up-regulated & HIF independent & N.D. & [52] \\
\hline \multicolumn{5}{|c|}{ HIF-mediated direct transcriptional regulation } \\
\hline HOTAIR & Up-regulated & HIF-1a dependent & ACACG $(-1118 /-1115)$ & [53] \\
\hline \multirow[t]{3}{*}{ H19 } & Up-regulated & HIF-1a dependent & ACGTG $(-111 /-107)$ & {$[54,71,72,122]$} \\
\hline & & & ACGTG (-398/-394) & \\
\hline & & & ACGTG (-1434/-1430) & \\
\hline \multirow[t]{2}{*}{ UCA1 } & Up-regulated & HIF-1a dependent & ACACG $(-1515 /-1511)$ & {$[55,123]$} \\
\hline & & & ACGTG (-53/-49) & \\
\hline NUTF2P3-001 & Up-regulated & HIF-1a dependent & TGGGCGTGGTG (-2114/-2104) & [56] \\
\hline EFNA3 & Up-regulated & HIF-1a dependent & ACGTG (-295/-299) & [57] \\
\hline \multirow[t]{3}{*}{ HINCUT-1 (UC.475) } & Up-regulated & HIF-1a dependent & GCTCGCATGCGCGG $(-527 /-514)$ & [58] \\
\hline & & & CACACGTGCGCG (-1233/-1222) & \\
\hline & & & CACGTGCGC (-1232/-1224) & \\
\hline ANRIL & Up-regulated & HIF-1a dependent & ACACG (-712/-708) & [59] \\
\hline \multirow[t]{2}{*}{ GAPLINC } & Up-regulated & HIF-1a dependent & ACGTG (-320/-324) & {$[60,90]$} \\
\hline & & & CACGC $(-578 /-582)$ & \\
\hline \multirow[t]{2}{*}{ lincRNA-p21 } & Up-regulated & HIF-1a dependent \& preference & CGTGTACCAC (-797/-788) & [61] \\
\hline & & & CGTGAGCCAC (+2603/+2612) & \\
\hline \multirow[t]{2}{*}{$a H I F$} & Up-regulated & HIF-1a and/or HIF-2a dependent & GCACG (-2045/-2049) & {$[62,73,85]$} \\
\hline & & & GCGTG (-2057/-2061) & \\
\hline MALAT1 & Up-regulated & HIF-2a dependent \& preference & CGCGCGTGCGCA $(-59 /-70)$ & {$[51,74,99,103,124]$} \\
\hline NEAT1 & Up-regulated & HIF-2a dependent \& preference & Identified by ChIP-Seq & {$[51,74,104,105]$} \\
\hline InCRNA-SARCC & VHL-dependent & HIF-2a dependent & ACGTGCTGA (-3258/-3250) & [70] \\
\hline \multicolumn{5}{|c|}{ HIF-mediated indirect epigenetic regulation } \\
\hline WT1-AS & Up-regulated & $\begin{array}{l}\text { HIF-1 dependent } \\
\text { (Indirect: DNA demethylation) }\end{array}$ & N.D. & [63] \\
\hline InCRNA-LET & Down-regulated & $\begin{array}{l}\text { HIF-1a dependent } \\
\text { (Indirect: Histone deacetylation) }\end{array}$ & N.D. & {$[68,80]$} \\
\hline \multicolumn{5}{|c|}{ Undetermined hypoxia-induced regulation } \\
\hline LnCHIFCAR (MIR31HG) & Up-regulated & HIF-1a dependent & N.D. & [64] \\
\hline linc- $R O R$ & Up-regulated & N.D. & N.D. & [49] \\
\hline InCRNA-AK058003 & Up-regulated & N.D. & N.D. & [50] \\
\hline NBR2 & Up-regulated & N.D. & N.D. & [65] \\
\hline IncRNA-AK123072 & Up-regulated & N.D. & N.D. & [66] \\
\hline PVT1 & Up-regulated & N.D. & N.D. & [67] \\
\hline ENST00000480739 & Down-regulated & N.D. & N.D. & [69] \\
\hline
\end{tabular}

Abbreviation: N.D. Not determined

response, although the underlying mechanisms remain largely unknown.

Recently, the number of HRLs that have been identified is expanding rapidly, illustrating the complexity of the hypoxia-induced gene reprogramming and the importance to re-consider the involvement of non-coding genome in this adaption. Oxygen deprivation could be acute, transient in local regions, whereas lncRNAs are matchlessly suited to exert a rapid, precise and reversible fine-tuning of the cellular response to this hypoxia stress due to their non-coding and quick biogenesis nature. Indeed, the network of HRLs and their downstream targets are demonstrated to offer the potential for a dynamic biological response to hypoxia. Accordingly, extensive molecular crosstalk between hypoxic signaling cascades and lncRNA metabolism has co- 
evolved to maintain such exquisite coordination of these adaptive programs.

In the present review, we aim to summarize the most recent findings concerning the tumor hypoxia-associated lncRNAs known to date, with a specific focus on the interplay among these non-coding transcripts and cellular hypoxia response. We describe recent models of molecular mechanisms in which these new players drive hypoxia-induced cancer progression, and attempt to address their relevant potential as clinical biomarker for early diagnosis and prognosis prediction, or even as therapeutic targets in tumor treatment strategies. Our discussion is largely limited to tumor hypoxia, and for roles of lncRNAs in hypoxia- or anoxia-induced cardiovascular and neuromuscular diseases, readers are referred to several excellent recent reviews on these topics [46-48].

\section{Review}

\section{Regulation of IncRNAs by hypoxia}

Given the relevance of HIF pathways on tumor pathogenesis and the pivotal roles of lncRNA in gene expression, it is not surprising that substantial effort has been directed toward defining the transcriptional output of lncRNA in hypoxia-associated malignant progression in the past few years. Increasingly, systematic approaches have been used to identify hypoxia-regulated lncRNAs. By qPCR examination on hypoxic regulation of 89 lncRNAs in hepatocellular cancer (HCC) cells, 20 lncRNAs were identified upregulated $>2$-fold while 18 downregulated [49]. Microarray analysis of hypoxic gastric cancer cells revealed that 84 lncRNAs were significantly upregulated whereas 70 were downregulated, as compared with normoxic cells [50]. More recently, a systematic analysis coupled RNA-seq with ChIP-seq in hypoxic MCF-7 breast cancer cells demonstrated that lncRNA expression is profoundly regulated by hypoxia. Moreover, the involvement of HIF in the transcriptional response of lncRNAs to hypoxia is far more extensive than previously appreciated [51]. However, in these investigations, the underlying mechanism by which these long noncoding transcripts were regulated upon hypoxia remains largely untouched. Moreover, considering the cell-type and tissue specificity of lncRNA expression, it is expected that there are many more hypoxiaresponsive lncRNAs await to be discovered.

Despite these pangenomic studies, a rapidly expanding repository of largely oncogenic lncRNAs have been reported individually to be regulated by hypoxia. Table 1 gives a brief summary to these hypoxia responsive lncRNAs. Among them, NOS3AS (the noncoding isoform of ATG9B; [52], HOTAIR [53], H19 [54], UCA1 [55], NUTF2P3-001 [56], EFNA3 [57], HINCUT-1 [58], ANRIL [59], GAPLINC [60], linc-p21 [61], aHIF [62], MALAT1 [51], NEAT1 [51], WT1-AS [63], LncHIFCAR
[64], linc-ROR [49], IncRNA-AK058003 [50], NBR2 [65],

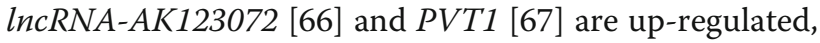
whereas $\operatorname{lncRNA-LET~[68]~and~ENST00000480739~[69]~}$ are down-regulated in response to hypoxia. Interestingly, IncRNA-SARCC could differentially respond to hypoxia in a VHL-dependent manner [70], while the regulatory mechanisms underlying the hypoxic altered expression of several HRLs still remained uncharacterized (Table 1).

It is well appreciated that the HIF complex is a crucial transcription factor coordinating cellular transcriptional response under hypoxic stress. According to their interplay with the HIF complex, the hypoxia responsive lncRNAs can be categorized into HIF-dependent and HIF-independent.

\section{HIF-independent regulation of hypoxia responsive IncRNA}

An antisense transcript of $e N O S$ (endothelial nitric-oxide synthase) mRNA, the noncoding isoform of $A T G 9 B$ (also known as eNOS antisense [NOS3AS] or autophagy 9like 2 [APG9L2]) induced by hypoxia, is the only one to date reported to be HIF-independent [52]. The hypoxic induction of this antisense transcript is mainly through transcript stabilization which in turn leads to eNOS expression suppression [52]. However, its involvement in tumorigenesis and even whether it acts as an RNA or a protein have not been completely elucidated [52].

\section{HIF-mediated direct regulation of hypoxia responsive IncRNA transcription}

In addition, a number of HIF-dependent HRLs have been studied in detail. Similarly with miRNAs and proteincoding genes, HIF could directly regulate lncRNAs at transcriptional level through HREs (hypoxia response elements) that usually reside within their promoter regions. By in silico prediction combined with biochemical assays such as ChIP (chromatin immunoprecipitation) and EMSA (electrophoretic mobility shift assay), a set of HREs responsible for hypoxic induction of lncRNAs have been identified (Table 1).

For instance, the promoters of HOTAIR, H19, lncRNAUCA1, IncRNA-NUTF2P3-001, lncRNA-EFNA3, HINCUTS, ANRIL, NEAT1, MALAT1 and GAPLINC are demonstrated to harbor functional HREs required for HIF-1 $\alpha$-mediated transcriptional activation under hypoxia. Notably, the interplay between HIF-1 and other transcription factors can impact on the induction of HRLs upon hypoxia. For instance, H19 expression is not affected in wild type $p 53$ cells, whereas it is dramatically upregulated in $p 53$ null cells, revealing that $p 53$ status may govern lncRNA expression under hypoxia [71] Meanwhile, in glioblastoma, the process of HIF- $1 \alpha$ binding to the H19 promoter requires SP1 (specific protein 1 ) to be activated by HIF-1 $\alpha$ [72]. Also, PTEN status is a critical factor affecting hypoxia-induced H19 level in multiple GBM cell lines and human clinical 
specimens [72]. In addition to HIF- $1 \alpha$, systematic ChIP-seq data of human hypoxic breast cancer cells revealed that, HIF- $2 \alpha$ also bound with lncRNA promoters and even in a higher proportion than HIF- $1 \alpha$, suggesting a pivotal role of HIF- $2 \alpha$ in the regulation of the long noncoding transcriptome upon hypoxia [50]. Indeed, both HIF- $1 \alpha$ and HIF- $2 \alpha$ proteins were shown to bind the HRE in the human aHIF gene specifically [73]. Notably, like hypoxia-responsive coding genes and miRNAs, both HIF- $1 \alpha$ and HIF- $2 \alpha$ regulate distinct but overlapping sets of lncRNAs. As an example, silencing of HIF- $1 \alpha$, but not HIF- $2 \alpha$, significantly attenuated hypoxia-induced lincRNA- $p 21$ upregulation [61]. Nonetheless, in the cases of NEAT1 and MALAT1 (also known as NEAT2) lncRNAs, the loss of function assays showed that HIF- $2 \alpha$, rather than HIF- $1 \alpha$, is the preferred transcriptional activator in MCF-7 cells [74]. Most intriguingly, IncRNA-SARCC (Suppressing Androgen Receptor in Renal Cell Carcinoma) could differentially respond to hypoxia in a von Hippel-Lindau (VHL)dependent manner [70]. It was shown that LncRNASARCC can be transcriptionally suppressed by HIF- $2 \alpha$ through HREs within its promoter. Moreover, the same study revealed a LncRNA-SARCC-mediated posttranscriptional regulation of androgen receptor (AR) by physically binding and de-stabilizing AR protein to suppress AR/HIF-2alpha/C-MYC signals. Along these lines, the negative feedback modulation between LncRNASARCC/AR complex and HIF- $2 \alpha$ signaling may thereby contribute to differential RCC progression in a VHLdependent manner [70]. Collectively, this work demonstrates that the hypoxia-responsive IncRNAs can be regulated at transcription level directly by HIF- $1 \alpha$ and/or HIF- $2 \alpha$ in a variety of cancers.

\section{HIF-mediated indirect regulation of hypoxia responsive IncRNA transcription}

Currently, several studies have described hypoxic induction of lncRNAs through mechanisms without the direct involvement of HIF on their promoters. These indirect regulation seems to be achieved through epigenetic mechanisms. Not surprisingly, as an integral hypoxic transcription factor, the HIF complex transactivates the expression of multiple genes, including those involved in epigenetic modifications among HDACs (histone deacetylases) tested in hepatocellular carcinoma SMMC-7721 cells in a recent study, only HDAC3 was specifically upregulated by hypoxic insult [68]. This hypoxia-induced HDAC3 suppressed IncRNA-LET expression by reducing the levels of histone $\mathrm{H} 3$ and $\mathrm{H} 4$ acetylation in the IncRNA-LET promoter region [68], revealing an indirect regulation mediated by HIF- $1 \alpha$.

In myeloid leukemia cells, another antisense RNA WT1-AS was reported to be regulated upon hypoxia in a similar way [63]. WT1-AS lncRNA is transcribed antisense from Intron 1 or from the same promoter region of WT1. Hypoxia provokes a decrease in expression and activity of DNMT1 (DNA methyltransferase 1) as well as an increase in expression and activity of the evolutionarily conserved dioxygenases TET2 (Ten-Eleven-Translocation 2) and TET3 (Ten-Eleven-Translocation 3), resulting in demethylation of the CpG island in Intron 1 of WT1 gene. This loss of methylation in WT1 Intron 1 CpG island therefore led to upregulation of both WT1-AS IncRNA and WT1 mRNA [63].

It is noteworthy that, in both cases of $\operatorname{lncRNA-LET\text {and}}$ WT1-AS, the hypoxia induced-modulation of IncRNA expression could be reverted by HIF- $1 \alpha$ knockdown, indicating the critical involvement of HIF-1 in these hypoxia-caused IncRNA expression alteration [63, 68]. Also, these findings together demonstrated that epigenetic modification of chromatin plays an important role in HIF-mediated indirect modulation on IncRNA expression under hypoxia.

\section{Regulation of hypoxia signaling by IncRNAs}

To date, most of the HRLs are functionally characterized with profound impact on tumorigenesis in a spectrum of cancer types. However, the vast majority of HRLs described have not yet been studied in mechanistic detail, while the few that have been mechanistically investigated might provide clues regarding their biological roles in response to hypoxia. An overview of the tumor hypoxiaassociated lncRNAs is shown in Table 2, categorized according to their underlying action mechanisms. Some HRLs directly affect HIF activity, while others may have indirect regulations. Notably, several HRLs might adapt more than one action mechanism. The accumulating discovery of novel HRLs with more thorough investigation will surely reveal additional scenarios.

\section{HRLs in epigenetic regulation}

One of the major recurring theme in lncRNA biology is their ability to recruit protein factors for regulation of chromatin states. This class of lncRNAs often function as critical cis- and trans-acting modulators of proteincoding gene expression. Recent genome-wide studies of RNA-protein interactions have demonstrated that chromatin-modifying complexes interact with a series of lncRNAs, suggesting that these transcripts might direct the recruitment of protein complex to specific genomic loci. For example, IncRNAs such as HOTAIR (HOX transcript antisense RNA) and ANRIL (also known as CDKN2B antisense RNA 1) have even been shown to interact with more than one histone-modifying complex, and therefore been proposed to coordinate the targeting of histone-modifying complexes [75]. Of note, these two antisense RNAs, HOTAIR and ANRIL, have been shown 


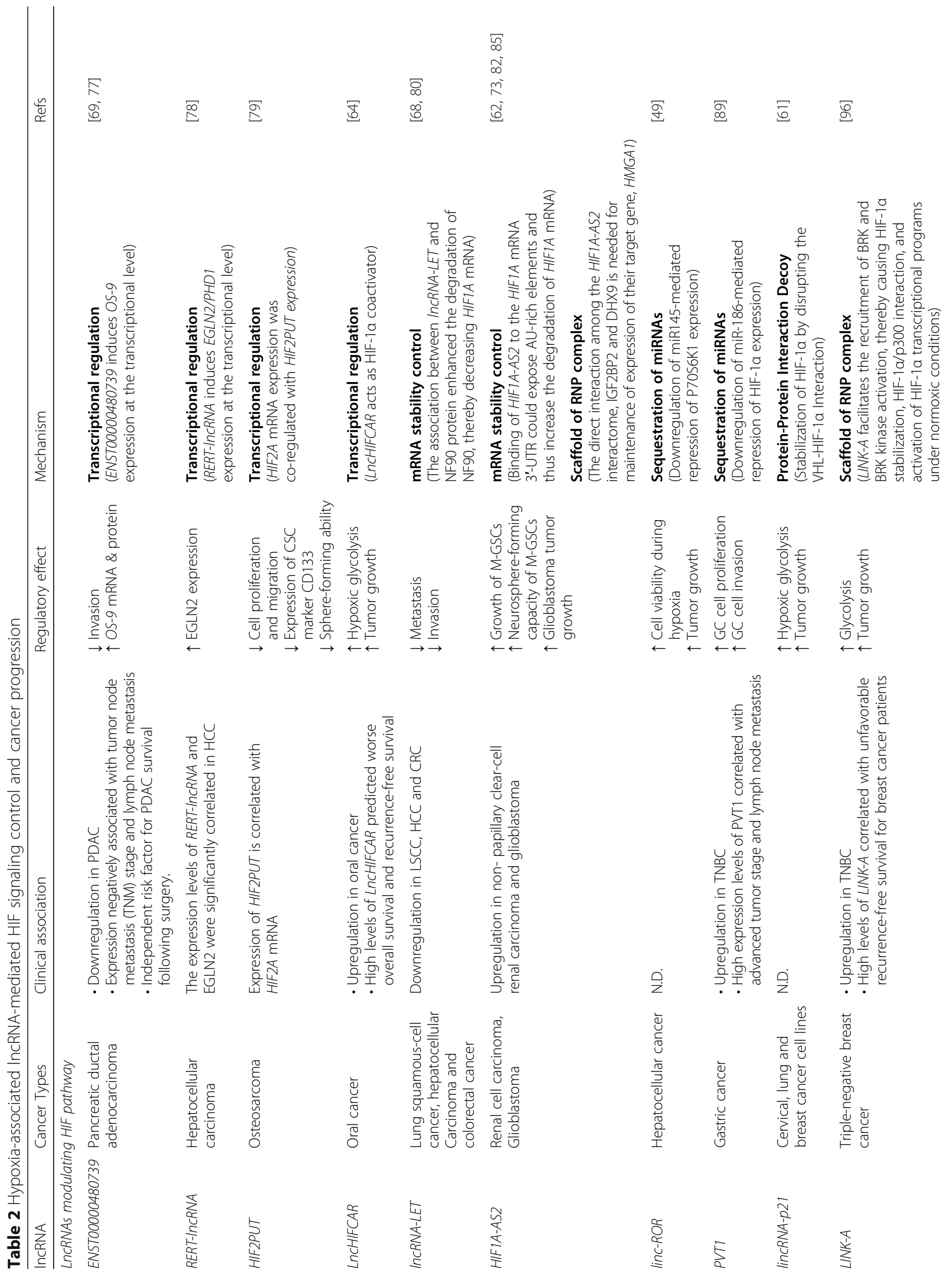




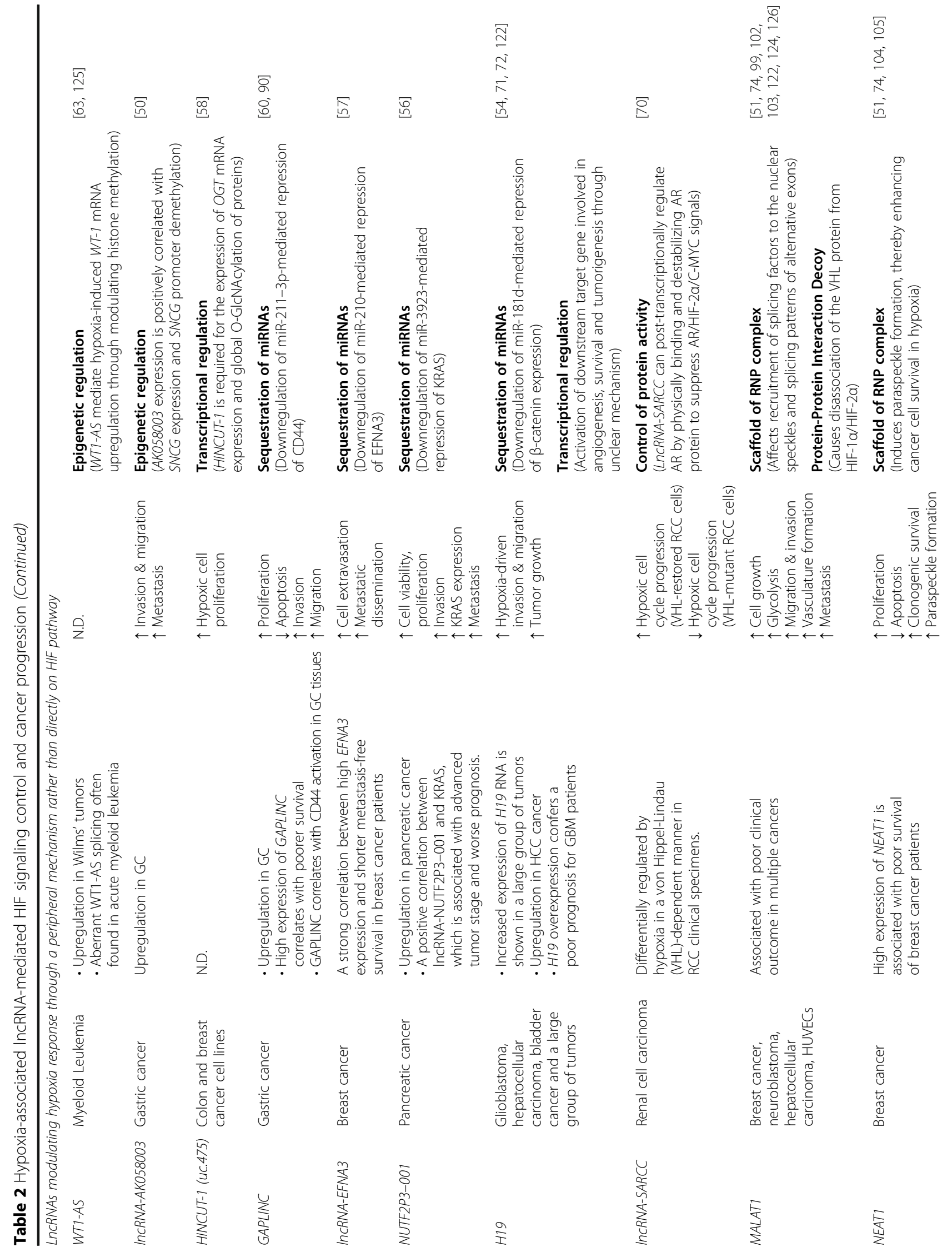




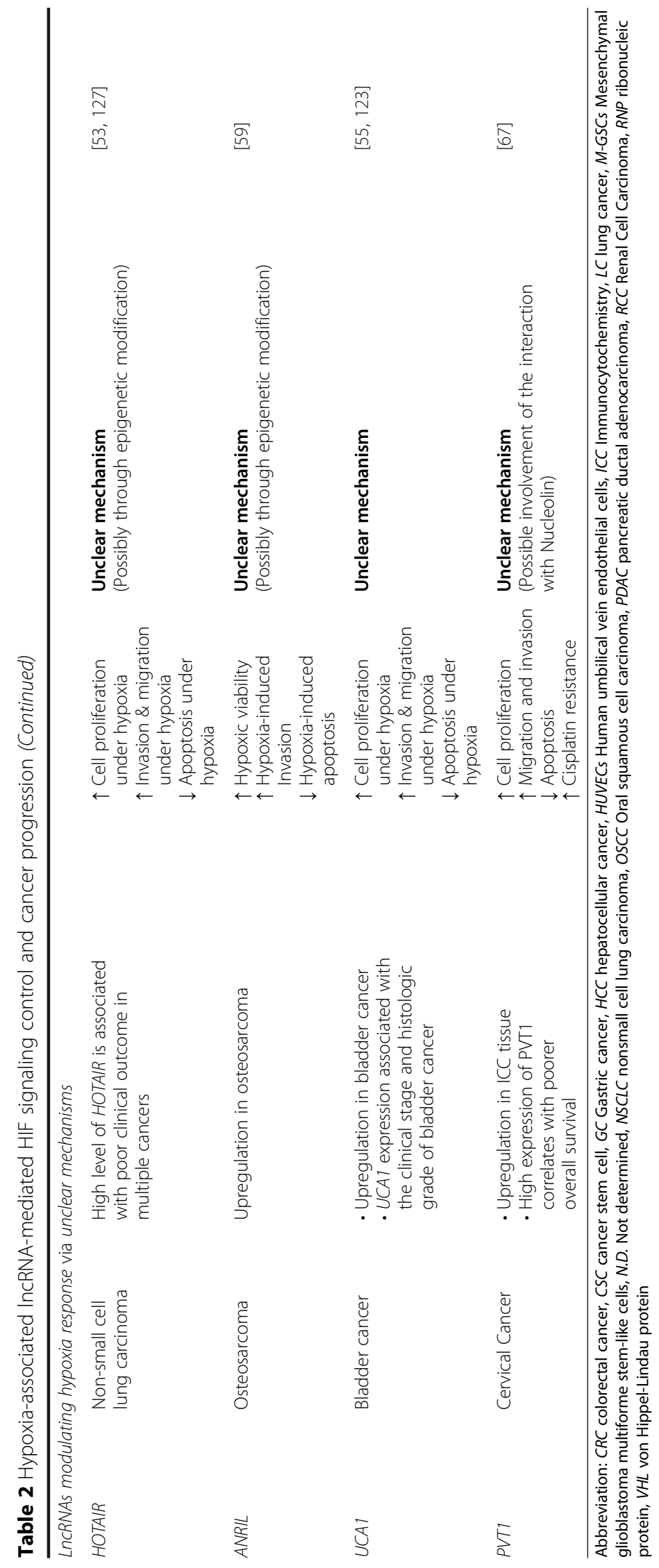


to be hypoxia-inducible and direct transcriptional targets of HIF, contributing to aggressive phenotype in lung cancer and osteosarcoma cells, respectively [53, 59]. However, whether these two asRNAs modulate hypoxic gene expression through epigenetic modification remains to be determined.

In addition, in myeloid leukemia cells, another hypoxiainducible antisense RNA, WT1-AS lncRNA, was reported to modulate histone methylation in cis at the WT1 mRNA transcription start site [63]. WT1 gene encodes a transcription factor WT1, which is overexpressed in a wide variety of tumor types, including acute myeloid leukemia (AML). Interestingly, WT1-AS lncRNA is transcribed antisense to $W T 1$ and observed to interact with sense WT1 mRNA, resulting in WT1 protein up-regulation [76]. Moreover, WT1-AS lncRNA could mediate hypoxiainduced WT-1 mRNA upregulation through modulating histone methylation H3K4me3 and H3K9me3 at the WT1 mRNA transcription start site, thus contributing to tumor progression [63]. This study showed that the hypoxiasensitive histone methylation changes in the WT1 locus are dependent upon WT1-AS lncRNA expression, and provided another model of HRP-mediated epigenetic regulatory mechanism.

Notably, in gastric cancer cells, IncRNA-AK058003, located upstream of synuclein gamma (SNCG, a metastasisassociated protein), is robustly upregulated by hypoxia and regulates SNCG expression in cis by demethylating CpG islands within its promoter, thereby promoting hypoxia-induced metastasis [50].

\section{HRLs in transcriptional regulation}

Aside from remodeling chromatin structure, several HRLs are found to modulate transcription and thereby affecting HIF activity via multiple mechanisms. For example, HRLs can influence the transcription of HIF regulatory factors and fine-tune the HIF network in an indirect way. In human PDAC (pancreatic ductal adenocarcinoma) cells, a novel lncRNA ENST00000480739 was identified to target HIF- $1 \alpha$ expression by upregulating OS-9 (osteosarcoma amplified-9) mRNA expression [69]. OS-9 is a HIF-1 $\alpha$-binding protein mediating destabilization of HIF- $1 \alpha$ by promoting the interaction between HIF-1 $\alpha$ and PHD (proline hydroxylase domain) proteins, which in turn facilitates HIF- $1 \alpha$ hydroxylation and proteasomal degradation [77] (Fig. 2a). Interestingly, ENST00000480739 is located upstream of the OS-9 promoter region and acts in cis to induce its transcription, leading to HIF- $1 \alpha$ downregulation in trans and suppression of tumor cell invasion [69]. Of note, ENST00000480739 expression level was remarkably decreased in PDAC, negatively associated with lymph node metastasis and an independent prognostic factor of PDAC patient survival following surgery [69], consistent with its regulatory role in HIF-1 $\alpha$-driven tumor metastasis and progression (Fig. 2a, Table 2).

Likewise, RERT-lncRNA overlaps with EGLN2 that encodes prolyl hydroxylase PHD1 responsible for HIF- $1 \alpha$ hydroxylation and degradation (Fig. 2a). In HCC (hepatocelluar carcinoma) cells, RERT-lncRNA was reported to suppress the HIF- $1 \alpha$ expression by upregulation of EGLN2 at the transcriptional level [78]. Although the expression of $R E R T-\ln c R N A$ in low-oxygen conditions has not been addressed in this study, it provides an example of IncRNA indirectly modulating HIF pathway through regulating EGLN2 expression (Fig. 2a, Table 2).

HIF2PUT (HIF- $2 \alpha$ promoter upstream transcript, previously known as TCONS_00004241) is another example of hypoxia-associated lncRNA acting in cis [79]. HIF2PUT was identified as an antisense lncRNA transcribed upstream of the promotor region of HIF2A mRNA. The lncRNAs of this category are known as PROMPTs (promoter upstream transcripts), which appear to modulate the transcriptional expression of host protein-coding genes. Indeed, in primary osteosarcoma tumors and cancer cell lines, HIF2PUT expression was co-regulated with HIF2A mRNA, whereas HIF2PUT expression alteration led to a parallel variation in $H I F 2 A$ mRNA expression [79]. However, the expression and role of HIF2PUT under hypoxia remained to be elucidated.

Interestingly, an ultra-conserved transcript, HINCUT-1 (hypoxia-induced noncoding ultra-conserved transcript 1 , also named as uc.475), is transcribed as a retained intron of OGT (O-linked $\mathrm{N}$-acetylglucosamine transferase) mRNA [58]. Being a direct transcriptional target of HIF$1 \alpha$, HINCUT-1 is overexpressed in colon and breast cancer cells under hypoxia and in primary colorectal tumors [58]. As HINCUT-1 knockdown reduced OGT gene and protein expression, it is suggested that HINCUT-1 transcript has a transcriptional activity [58]. Intriguingly, the HINCUT-1 DNA region was demonstrated to exhibit an enhancer-like activity both under hypoxia and normoxia, revealing its multifaceted regulatory roles in gene transcription [58].

Moreover, HRLs could act directly on specific transcription factors. More recently, we identified LncHIFCAR (long noncoding HIF- $1 \alpha$ co-activating RNA, previously known as MIR31HG) as another hypoxia-inducible lncRNA. LncHIFCAR acts as a critical mediator in hypoxia-associated tumorigenesis steps, including hypoxic cell growth, metabolic regulation, stem-like properties and metastatic potential in oral cancer [64]. Mechanistically, we described a distinct mechanism, independent of the stabilization or translocation of HIF- $1 \alpha$, in which LncHIF$C A R$ serves as an oncogenic HIF- $1 \alpha$ co-activator through direct binding to HIF- $1 \alpha$, thereby facilitating the recruitment of HIF- $1 \alpha$ and p300 cofactor to the target promoters. The increased abundance of the HIF complex 


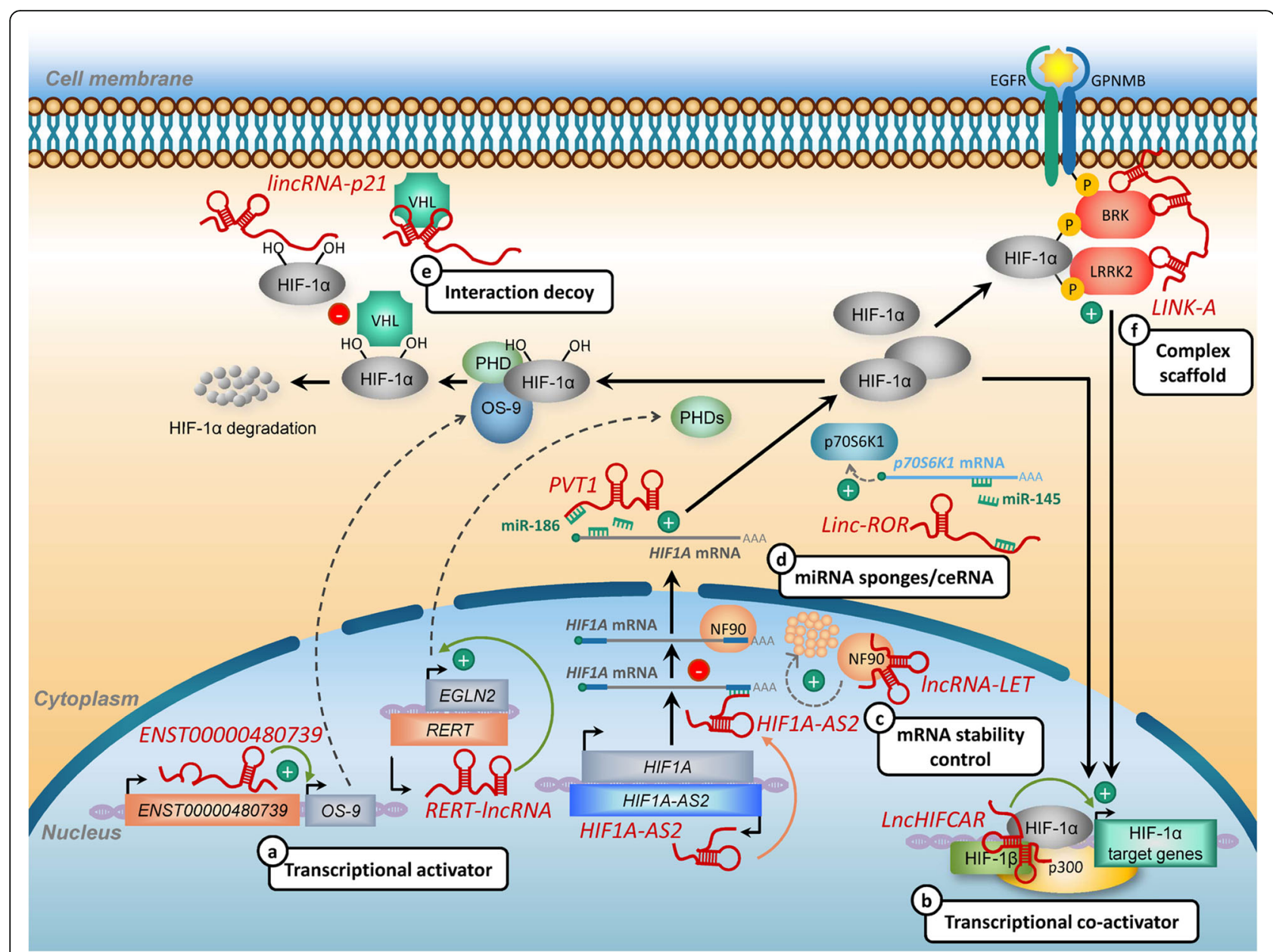

Fig. 2 Mechanisms of hypoxia-reponsive IncRNAs affecting HIF-1a activity. a Transcriptional activator. IncRNA ENST00000480739 suppresses HIF-1a expression by upregulating OS-9 transcription. OS-9 is a HIF-1a-binding protein that facilitates HIF-1a hydroxylation and proteasomal degradation. Another IncRNA RERT-InCRNA decreases the HIF-1a levels by upregulation of EGLN2 mRNA. EGLN2 encodes prolyl hydroxylase PHD1, which is responsible for HIF-1a hydroxylation and promoting HIF-1a degradation. b Transcriptional co-activator. LnCHIFCAR acts as an oncogenic HIF-1a co-activator through direct binding to HIF-1a, thereby facilitating the recruitment of HIF-1a and p300 cofactor to the target promoters and stimulating HIF-1 target gene expression. c mRNA stability control. IncRNA-LET interacts with RNA-binding protein NF90, which has been implicated in the stabilization of target mRNAs. As the association between IncRNA-LET and NF90 could enhance the degradation of NF90, the hypoxia-induced downregulation of IncRNA-LET may thereby increase HIF-1A mRNA stability under hypoxic conditions. In addition, IncRNA HIF1A-AS2, an antisense transcripts transcribed from the 3'-UTR of the sense HIFTA mRNA negatively regulates HIF1A mRNA expression. Through base-pair binding to the HIF-1A mRNA 3'-UTR, HIF1A-AS2 could expose AU-rich elements within the HIF-1A mRNA 3'-UTR, thereby destabilizing of HIF-1A mRNA. $\mathbf{d}$ miRNA sponge/ceRNA. miR-145 negatively regulates expression of p70S6K1, a protein kinase responsible for promoting protein synthesis. Hypoxia-induced lincRNA-ROR could upregulate HIF-1a expression by sequestering endogenous miR-145. In addition to lincRNA-ROR, PVT1 IncRNAs upregulate HIF-1a expression by sponging miR-186. e Interaction decoy. lincRNA-p21 is capable of binding to both VHL and HIF-1a, leading to disruption of VHL/HIF-1a interaction. f LINK-A recruits and activates BRK and LRRK2 to phosphorylates HIF-1a. These phosphorylation modifications prevents HIF-1a degradation under normoxia and facilitates the interaction between HIF-1a and cofactor p300, thereby activating HIF-1 target genes. See text for detailed discussion

work in concert to further stimulate the hypoxia-induced HIF-1 transcriptional reprogramming and subsequent cancer progression [64]. Remarkably, our results also uncovered the up-regulation of LncHIFCAR in oral carcinoma and the clinical relevance of LncHIFCAR as an independent adverse prognostic predictor for the cancer progression [64] (Fig. 2b, Table 2). Notably, with the extraordinary variety of transcriptional regulatory mechanisms discussed here, it is expected that additional means of
lncRNAs adapted for fine-tuning hypoxia-induced transcriptional regulation are likely to be uncovered in the near future.

\section{HRLs in post-transcriptional control}

Once transcribed, eukaryotic mRNAs are subjected to a series of post-transcriptional control of gene expression, including mRNA decay and miRNA-mediated repression. Accumulating data shows that, during hypoxia, 
these post-transcriptional events could be centrally controlled by HRLs.

mRNA stability control Two HRLs lncRNA-LET (Long noncoding RNA Low Expression in Tumor) and HIF1A-AS2 (HIF1A Antisense RNA 2; also known as $a H I F)$ have both been implicated in both negative regulation of HIF1A mRNA stability. Unlike most of hypoxia-responsive lncRNAs reported, $\ln c R N A-L E T$ expression is suppressed upon hypoxia due to activation of HDAC3 [68] as mentioned above. $\operatorname{lncRNA-LET~was~}$ found to be generally downregulated in various types of tumors, including hepatocellular carcinomas, colorectal cancers, squamous-cell lung carcinomas and gallbladder cancer $[68,80]$. Mechanistically, $\operatorname{lncRNA-LET~could~}$ interact with RNA-binding protein NF90 (nuclear factor 90), which has been implicated in the stabilization of several target mRNAs [81]. As the association between IncRNA-LET and NF90 was shown to enhance the degradation of NF90 [68], the hypoxia-induced downregulation of $\ln C R N A-L E T$ may thereby increase HIF-1A mRNA stability under hypoxic conditions and lead to hypoxiainduced cancer cell invasion (Fig. 2c, Table 2). Notably,

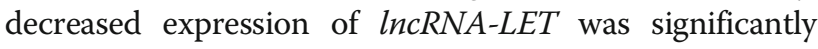
correlated with tumor micrometastases and encapsulation in HCC [68], while the similar association with low differentiated histology, advanced tumor status, and nodal status was also reported in primary gallbladder cancer [80]. Multivariate analysis revealed $\operatorname{lncRNA-LET}$ as an independent prognostic marker for metastasis and death in gallbladder cancer patients [80].

In addition, IncRNA HIF1A-AS2, an antisense transcripts transcribed from the 3 '-UTR (untranslated region) of the sense HIF1A mRNA, was found to be hypoxia-inducible [62], upregulated in various tumors [62, 82-85] and negatively regulates HIF1A mRNA expression [73, 82]. More specifically, through base-pair binding to the HIF-1A mRNA 3'-UTR, HIF1A-AS2 could expose AU-rich elements within the HIF-1A mRNA 3 '-UTR, thereby destabilizing of HIF-1A mRNA [82] (Fig. 2c, Table 2). More recently, lncRNA HIF1A$A S 2$ was also found to be selectively induced in mesenchymal GSCs (glioblastoma stem-like cells) in response to hypoxia [85]. HIF1A-AS2 promotes tumorigenicity and required for hypoxia-dependent molecular reprogramming in GSCs [85]. Other than impact on RNA stability, HIF1A-AS2 could enhance the expression of several of mRNA targets, such as HMGA1 (high mobility group AT-hook 1) mRNA, and subsequent molecular response to hypoxic stress through the direct interaction with IGF2BP2 (insulin-like growth factor 2 mRNAbinding protein 2) and DHX9 (ATP-dependent RNA helicase A) [85], which suggests IncRNA HIF1A-AS2 may modulate gene expression via multiple mechanisms.
miRNA sponges Functional manipulations of HRLs have demonstrated that several HRLs have roles in hypoxia response by acting as a 'competitive endogenous RNA (ceRNAs)' network and by participating in endogenous miRNA 'sponges' or 'decoys' to interfere with miRNA-mediated mRNA destabilization. In recent years, it has been postulated that a genome-wide regulatory network exists between coding and non-coding RNAs that manifests through competition for miRNA binding. A number of mammalian lncRNAs, including lincRNA-ROR, PVT1, GAPLINC, EFNA3, H19 and NUTF2P3-001 have miRNA-binding sites and therefore act as "miRNA sponges" to sequester miRNAs away from their mRNA targets (Table 2). Specifically, in HCC cells, hypoxia-induced lincRNA-ROR could upregulate HIF- $1 \alpha$ expression by sequestering endogenous miR-145 [49]. Remarkably, miR-145 inhibits p70S6K1 post-transcriptional expression by targeting its 3 '-UTR, whereas the downstream molecules of p70S6K1, HIF-1, is also simultaneously decreased upon miR-145 overexpression. [86]. Accordingly, by nullifying miR-145, lincRNA-ROR indirectly activates HIF- $1 \alpha$ expression (Fig. 2d, Table 2) [49].

In addition to lincRNA-ROR, PVT1 lncRNA also functions most likely in this way. In cervical cancer, PVT1 expression is shown to be upregulated in response to hypoxia and immune response stimulation [67]. This transcript has been designated as an oncogenic role due to its contribution to the aggressive phenotype of multiple cancers, including cervical cancer and gastric cancer [67, 87-89]. In gastric cancer cells, PVT1 was demonstrated to upregulate HIF- $1 \alpha$ expression by sponging miR-186 to revert miR-186-mediated repression of HIF$1 \alpha$ expression and consequentially promote $\mathrm{GC}$ cell progression indirectly [89] (Fig. 2d, Table 2).

Likewise, some of the HRLs may regulate other hypoxia-associated proteins than HIF- $1 \alpha$ via functioning as a ceRNA. A typical example among this kind of HRLs is GAPLINC (Gastric Adenocarcinoma Associated, Positive CD44 Regulator, Long Intergenic Non-Coding RNA). In gastric cancer, GAPLINC is directly activated by HIF- $1 \alpha$ and its overexpression is associated with poor prognosis and could promote tumor migration and invasive behavior [60]. Echoing these results, GAPLINC was shown to enhance tumor migration and invasion by acting as a molecular decoy for miR-211-3p to rescue CD44 expression [90].

Aside from GAPLINC, EFNA3 lncRNA was shown to be induced in hypoxic breast cancer cells and also to function in this way [57]. EFNA3 IncRNAs are transcribed from the EFNA3 locus which also encoded Ephrin-A3, a signaling ligand crucial for tumor metastasis and extravasation. EFNA3 lncRNAs refer to 4 different isoform according to different transcription start 
sites and truncated 3'-UTR [57]. Upon hypoxia, hypoxia-induced miR-210 can target 3'-UTR of EFNA3 mRNA and prevent its translation of [91-93]. More interestingly, with the same 3'-UTR region, EFNA3 lncRNAs could increase EFNA3 mRNA translation by depleting miR-210 [57], revealing a mechanism by which hypoxia-induced EFNA3 lncRNAs act as ceRNAs that relieve EFNA3 mRNA from miRNA repression allowing for efficient transcription during hypoxia.

In pancreatic cancer, IncRNA-NUTF2P3-001 is identified as a hypoxia-inducible gene and a HIF- $1 \alpha$ direct transcriptional downstream target [56]. Overexpression of lncRNA-NUTF2P3-001 is found in pancreatic cancer tissue and associated with advanced tumor stage and poor prognosis [56]. Similarly, IncRNA-NUTF2P3-001 has been suggested to act as a 'sponge' that inhibits miR3923 that targeted KRAS, a critical driver in pancreatic cancer tumorigenesis [56].

In particular, lncRNA H19, the mammalian imprinted transcript, was among the first reported hypoxia-regulated lncRNAs [54]. Upon hypoxia, HIF-1 $\alpha$-dependent H19 expression is robustly upregulated in hepatocellular and bladder carcinoma [54]. In the past few years, H19 has been implicated as an oncogene in various cancers including gastric, bladder, colorectal and breast cancers, and its action mechanism can be dissected into two major categories: a reservoir of miR-675 that suppresses its targets, and a modulator of miRNAs or protein factors through their interactions [94]. More recently, in glioblastoma, hypoxia-induced H19 upregulation was reported to drive an aggressive phenotype by absorbing miR-181d and aborting the miR-181d-mediated repression on $\beta$-catenin, an oncogenic factor associated with EMT (epithelialmesenchymal transition) [72].

Collectively, it seems quite feasible that the long and small non-coding RNA systems would eventually intertwine to form mutually reciprocal repression feedback networks. In this scenario, any alteration in the expression level of one member in this network, and accordingly the amount of miRNAs associated with it, would disturb the overall accessible pool of ncRNAs, resulting in concordant shift to transcriptional reprogramming. To delineate this new layer of post-transcriptional regulation directed by hypoxia responsive ceRNAs, it will be of interest to further explore the relevant coworking relationships between lncRNAs and miRNAs under hypoxia.

\section{HRLs in control of protein activity and/or higher-order complex formation}

Apart from HRLs-exerted modulation of gene expression events through interplay with other RNAs, HRLs can also act on the protein level. It is well known that RNA transcripts could associate with proteins to form ribonucleoprotein particles (RNPs) to exert their functions. To date, our knowledge of the lncRNA-containing RNPs is relatively limited compared to those composed of other RNAs, such as rRNAs and snRNAs. Along these lines, lncRNA/protein interaction network in cells could provide delicate means to fine-tune gene expression. For instance, as mentioned above, LncRNA-SARCC could exert post-transcriptional regulation of AR through physical interaction and de-stabilizing $A R$ protein to repress AR/HIF-2 $\alpha / C-M Y C$ signaling [70]. In cervical cancer, hypoxia-inducible lncRNA PVT1 (plasmacytoma variant translocation 1) was suggested to exert its oncogenic role through association with the multifunctional protein, Nucleolin [67]. Nevertheless, there are several reports showing that, in addition to modulating single protein activity, HRLs can also act as decoys or scaffolds to elicit direct impacts on the formation of higher-order RNP complexes.

LincRNA-p21, directly activated by HIF- $1 \alpha$ at transcriptional level in low-oxygen conditions, provides an example to illustrate the complex formation [61]. LincRNA-p21 was capable of binding to both VHL and HIF-1 $\alpha$, resulting in disrupting the VHL/HIF-1 $\alpha$ interaction. Given that VHL-binding is essential for hydroxylation of the HIF-1 $\alpha$ protein and the following degradation via the ubiquitinproteasome pathway, lincRNA-p21-driven disassociation of VHL from HIF-1 $\alpha$ by binding to each of them could thereby attenuate VHL-mediated HIF-1 $\alpha$ ubiquitination and increase HIF- $1 \alpha$ accumulation under hypoxia (Fig. 2e, Table 2) [61]. Being a direct transcriptional target of HIF- $1 \alpha$, lincRNA- 21 itself generates a positive feedback loop promoting HIF-dependent pathways such as hypoxic glycolysis and Warburg effect [61]. Also noted, lincRNA-p21 was first identified as a key repressor in p53-dependent transcriptional responses through the physical association with hnRNP-K (heterogeneous nuclear ribonucleoprotein $\mathrm{K}$ ), which is necessary for accurate genomic localization of hnRNPK at repressed gene locus and control of p53-driven apoptosis [95]. Together, these results suggest, through association with different protein factors, one lncRNA may initiate diverse transcriptional programs.

In TNBC (triple-negative breast cancer), a highly prognostic lncRNA, LINK-A (long intergenic non-coding RNA for kinase activation) plays a pivotal role for the growth factor-induced normoxic HIF1 signaling [96], although its expression upon hypoxia remains to be determined. LINK-A interacts with two protein kinases BRK (breast tumor kinase) and LRRK2 (leucine-rich repeat kinase 2). This RNP complex could transfer signal from EGFR (epidermal growth factor receptor): GPNMB (transmembrane glycoprotein NMB) membrane heterodimer receptor to the nucleus by phosphorylation of HIF-1 $\alpha$ (Fig. 2f, Table 2). More specifically, 
upon receiving signal triggered by HB-EGF (heparinbinding EGF), LINK-A recruits BRK and LRRK2 to EGFR:GPNMB heterodimer, thereby inducing conformation changes and activating their kinase activities. The activated BRK and LRRK2 phosphorylates HIF- $1 \alpha$ at Tyr 565 and Ser 797, respectively. Notably, Tyr 565 phosphorylation inhibits adjacent Pro 564 hydroxylation, which prevents HIF-1 $\alpha$ degradation under normoxia, while Ser 797 phosphorylation facilitates the interaction between HIF- $1 \alpha$ and cofactor p300, activating HIF-1 target genes in response to HB-EGF stimulation [96]. Both LINK-A expression and the activation of HIF-1 signaling correlate well with TNBC, promoting glycolysis reprogramming, angiogenesis and tumorigenesis in breast cancer [96].

In many studies, MALAT1 (metastasis-associated lung adenocarcinoma transcript 1, also known as NEAT2) and NEAT1 (nuclear enriched abundant transcript 1) are another two hypoxia-induced lncRNAs via HIF binding to their promoter regions (Table 1). Both of them are highly conserved lncRNAs that localize to specific nuclear compartments [97] and are expressed from adjacent single exon genes on chromosome 11q [51]. MALAT1 is an intensively-studied lncRNA and frequently upregulated in various cancers, such as breast cancer, lung cancer and colon cancer, in which it promotes cellular proliferation, angiogenesis, tumor growth and metastasis [98-100], implying its potential as a cancer biomarker and a promising target for cancer therapy.

MALAT1 is a nuclear-retained lncRNA, implicating its function in nuclear processes, such as nuclear architecture organization, splicing, and gene expression. Indeed, MALAT1 is a core component of the nuclear speckles (also known as SC35 splicing domains or interchromatin granule clusters). As these nuclear structures are enriched with poly-adenylated RNAs and factors involved in mRNA processing, splicing, and export, the localization of MALAT1 reveals a role in RNA metabolism [101]. Though the overall assembly of nuclear speckles is not dependent on the attendance of MALAT1, MALAT1 associates with splicing factors and is required for their recruitment to the nuclear speckles, where they affect the alternative splicing patterns of exons $[97,100]$. In addition, other studies have shown that MALAT1 regulates alternative splicing by modulating phosphorylation of pre-mRNA splicing factors [102]. However, its role in regulating RNA splicing during hypoxia remains to be determined. Recently, MALAT1 has also been linked to the transcriptional and/or posttranscriptional control of gene expression via interactions with a series of specific factors, such as transcriptional coactivators, histone methyltransferases/demethylases and pre-mRNA splicing factors [100]. Also, one recent study suggested that, in hepatic cells, arsenite-induced
MALAT1 could enhance the disassociation of VHL from HIF-1 $\alpha$, attenuating VHL-mediated HIF- $1 \alpha$ ubiquitination, which in turn causes HIF- $1 \alpha$ accumulation and arsenite-induced glycolysis [103]. Collectively, to interpret the varying findings in different model systems, it is proposed that the function of MALAT1 is determined by the combination of interacting factors [100]. Feasibly, associations with divergent protein partners or nucleic acids could augment the spectrum of MALAT1 functions. Otherwise, MALAT1 may function as a "nuclear reservoir" for capture and storage of RNAs and their associated proteins.

In contrast to its neighboring lncRNA MALAT1 which does not significantly affect the formation of the nuclear speckles, IncRNA NEAT1 is an essential architectural component for nuclear paraspeckle assembly [97, 100]. The exact biological function of paraspeckles is currently unclear, but implicated in gene expression through the retention of hyper-edited RNA transcripts and other multifunctional protein components in paraspeckles to prevent their potential translation and activity [104]. Particularly, the hypoxic induction of nuclear paraspeckles leads to the nuclear retention of one such transcript, F11R (F11 receptor, also known as junctional adhesion molecule 1, JAM1) mRNA which was shown to be subjected to A-to-I editing $[105,106]$. However, suppression of NEAT1 abrogated hypoxia-induced nuclear retention of F11R mRNA, conferring a role of NEAT1 in nuclear retention of mRNAs during hypoxia [105]. Notably, induction of NEAT1 in hypoxia also leads to hallmarks of increased tumorigenesis, including acceleration of cell proliferation, promotion of cell survival, and reduced apoptosis [105]. Moreover, in patients with breast cancer and prostate cancer, high tumor NEAT1 expression correlates with poor survival $[105,107]$. As both MALAT1 and NEAT1 are implicated in control of nuclear structures, it will be interesting to further explore the extent to which these hypoxiainduced nuclear structures contribute to the regulation of other hypoxia-responsive genes.

\section{Conclusion and future perspectives}

The cellular adaption in response to hypoxia requires the precisely orchestrated regulatory network. The aforementioned discussion has provided a summary of our current knowledge regarding the expression, functions and mechanisms of hypoxia-responsive lncRNAs (HRLs). These novel mechanisms reveal a predominant, unanticipated role of HRLs in the control of gene expression under hypoxia and illustrates the elaborate network among the different classes of RNAs, including lncRNAs, miRNAs and mRNAs. Indeed, it has been reported that HIF is a major regulator of the coding and non-coding transcriptome [51, 108]. On the contrary, some lncRNAs 
described above regulate HIF activity and stabilization, adding an additional layer of complexity to the role of lncRNAs in gene expression control during hypoxia. Therefore, identification and characterization of the complete set of non-coding transcripts involved in the adaptation to limited oxygen supply is of utmost relevance for a deeper understanding of hypoxia-associated tumorigenesis steps.

The emergence of HRLs as important elements of cellular adaptation to hypoxia has prompted intense interest in elucidating how hypoxia controls HRL expression. The vast majority of studies have focused on the hypoxia-induced altered transcript abundance of HRLs. It is worth noting that many HRLs express multiple splice isoforms. As our understanding of HRLs advances, it will be equally important to uncover the hypoxiamediated modulatory effects on HRLs at other levels of biogenesis. Recent work has demonstrated the association between hypoxia and alternative spicing mechanisms that may have a direct impact on HRL expression [109]. It is also revealed that hypoxia could induce adenosine-toinosine (A-to-I) RNA sequence editing [110]. In addition, a wealth of evidence indicate that RNA bioactivity and stability are influenced by interactions with RNA binding proteins and/or RNA helicases $[111,112]$. These additional levels of post-transcriptional control may also participate in the distinctive shifts in HRL activity patterns upon low oxygen tension.

One particularly well-characterized mechanism, the so-called "ceRNA (competing endogenous RNA)" or "RNA sponges", by which HRLs regulate gene expression involves the interaction with miRNAs in a manner that can sequester these molecules and reduce their inhibitory effect on target mRNA (Fig. 2d, Table 2). Of note, it is postulated that ceRNA mechanism can only work under certain appropriate stoichiometry between miRNAs and ceRNA [113]. Therefore, beyond the presence of matching miRNA seed sequences, experimental evidence and knockout studies are required to further corroborate ceRNA mechanisms. Additionally, thorough investigation is needed to decipher the complex regulatory relationships existing among hypoxia-regulated lncRNAs and miRNAs. Target affinity of HRLs for a single miRNA or even a group of miRNAs may be modulated upon hypoxia. Given that numerous lncRNAs are host of miRNAs, the presence of poly-cistronic non-coding genes along with genomic miRNA clusters and overlapping targets suggest that conjunctional control is a fundamental theme of non-coding RNA biology. Currently, better in silico tools are necessary to predict integrated ceRNA effects during cellular response to hypoxia. Together, addressing these unsolved concerns regarding HRL biology will directly advance our knowledge of their role in adaptive responses and hypoxia-induced tumorigenesis.
Hypoxia-inducible factor (HIF) is central in coordinating HRL expression during exposure to low oxygen levels. Notably, mounting evidence implicates a number of other transcription factors and HIF-independent pathways involving p53, NF- $\mathrm{kB}, \mathrm{mTOR}$, endoplasmic reticulum (ER) stress and the unfolded protein response (UPR) play critical complementary roles in hypoxic transcriptional shift of coding genes [114, 115]. Consistent with this notion, IncRNA H19 expression under hypoxia is dependent on the status of $p 53$ [71], SP1 and PTEN [72], whereas the expression of $\ln c R N A-S A R C C$ could differentially respond to hypoxia in a VHL-dependent manner [70]. The possible involvement of other transcription factors and pathways may account for the widespread context dependency of hypoxia-mediated regulation on HRL expression, such as the different expression patterns of lncRNA HIF2CUT $[79,116]$ and HIF1A-AS2 [62] in a variety of cancers. This context dependence would surely have vital implications for the consideration of HRLs for possible applications. Therefore, in-depth future investigation is required to characterize the molecular details of how hypoxia elicts divergent effects on the expression of select subsets of HRLs.

Given the prominent biological and pathological roles played by HRLs in hypoxia-driven cancer progression, these transcripts may be exploited as valuable indicators of the intrinsic characteristics of the tumors, or as novel prognostic tools to aid in disease outcomes prediction, cancer patient assessment and management (Table 2). Moreover, considering the prevalence of hypoxiainduced metastasis, these findings suggest that individual HRLs or RNA panels combined with the expression signatures of prevailing mRNA, HRL and miRNA could potentially be utilized as tailored biomarkers for monitoring tumor hypoxia and metastasis. Compared with the current DNA, mRNA, or protein biomarkers, using lncRNA as biomarker for cancer diagnosis and prognosis has been shown to hold several advantages in light of its sensitivity, specificity, stability and easy accessibility [41]. Most remarkably, lncRNAs can be easily detected from the body fluid such as saliva, urine or blood [117]. Accordingly, the genome-wide identification and functional annotation of tissue-specific HRL signatures in conjunction with their expression patterns in tumors hold promising potential for the development of accurate, non-invasive biomarkers for early tumor detection and prognosis prediction. Nevertheless, in the past decade, GWASs (Genome-wide association study) have become a mainstream way to identify germline SNPs that may predispose individuals to cancer. Notably, structural approaches have revealed that even SNPs can change local RNA structure at functionally relevant sites required for miRNA or protein binding [118]. Although the relationship between HRLs and 
SNPs remains largely elusive currently, the identification of HRLs harboring cancer-associated SNPs by the use of GWAS data may help to categorize patient populations at risk of cancer, disease phenotypes and patient outcomes. Hence, the clinical translation of HRL-related SNPs in GWAS data may warrant future research attention relates to cancer epidemiology.

For decades, HIF-1 and its downstream effectors that mediate tumor metabolic adaptation, have been long recognized as potential targets for cancer drug due to their profound impacts in cancer progression. However, considering the complexity of the HIF- $1 \alpha$ signaling network and the requirements of targeting protein-protein interactions, it becomes extremely challenging to design HIF- $1 \alpha$ inhibitors. Recently, HRLs has been increasingly considered as potential cancer therapeutic targets owing to their tissue specificity, high expression levels and crucial roles in tumor growth and progression [41]. Till now, the development of RNA-targeting methods has provided tremendous opportunities to modulate lncRNAs for cancer therapy $[119,120]$. Most excitingly, novel classes of RNA-based therapeutics show great potential to modulate lncRNA activity in diverse ways [121]. Splice-switching oligonucleotides could redirect alternative splicing to restore gene function. Moreover, steric blocking oligonucleotides or small molecule could impede the interaction between IncRNAs and their binding partners. Although most lncRNA-targeted treatments remains in the early stages of development, future technical innovations along with better insights into lncRNA pathways in cancer biology will provide new opportunities. With in-depth characterization of both hypoxic microenvironment and non-coding RNA network, more hypoxia-responsive lncRNAs will be undoubtedly exploited as targets and stimulate development of ideal therapeutics for tumor patients in the near future.

\section{Additional file}

Additional file 1: Table S1. Hypoxia-responsive IncRNAs. (DOCX 19 kb)

\footnotetext{
Abbreviations

ANRIL: Antisense RNA in the INK4 locus; BRK: Breast tumor kinase; ceRNA: Competitive endogenous RNA; CRC: Colorectal cancer; CSC: Cancer stem cell; DHX9: ATP-dependent RNA helicase A; EGFR: Epidermal growth factor receptor; EMT: Epithelial-mesenchymal transition; ER: Endoplasmic reticulum; GAPLINC: Gastric adenocarcinoma associated, positive CD44 regulator, long intergenic non-coding RNA; GC: Gastric cancer; GPNMB: Transmembrane glycoprotein NMB; GSC: Glioblastoma stem-like cells; GWAS: Genome-wide association study; H19: Imprinted maternally expressed transcript; HBEGF: Heparin-binding EGF; HCC: Hepatocellular cancer; HIF1A-AS2: HIF1A Antisense RNA 2; HIF2PUT: HIF-2a promoter upstream transcript; HINCUT1: Hypoxia-induced noncoding ultra-conserved transcript 1; HMGA1: High mobility group AT-hook 1; HOTAIR: HOX transcript antisense RNA; HUVECs: Human umbilical vein endothelial cells; ICC: Immunocytochemistry; IGF2BP2: Insulin-like growth factor 2 mRNA-binding protein 2; LC: Lung cancer; linc-ROR: Long intergenic non-protein coding RNA, regulator of reprogramming; LINK-A: Long intergenic non-coding RNA for kinase activation; LncHIFCAR: Long noncoding HIF-1a co-activating RNA;
}

IncRNA: Long non-coding RNA; IncRNA-LET: Long noncoding RNA Low Expression in Tumor; IncRNA-SARCC: LncRNA-Suppressing Androgen Receptorin Renal Cell Carcinoma; LRRK2: Leucine-rich repeat kinase 2; MALAT1: Metastasis associated lung adenocarcinoma transcript 1; MGSCs: Mesenchymal glioblastoma multiforme stem-like cells; N.D.: Not determined; NBR2: Neighbor Of BRCA1 Gene 2; ncRNA: Non-coding RNA; NEAT1: Nuclear paraspeckle assembly transcript 1; NF90: Nuclear factor 90; NSCLC: Non-small cell lung carcinoma; OGT: O-linked N-acetylglucosamine transferase; OS-9: Osteosarcoma amplified-9; OSCC: Oral squamous cell carcinoma; PDAC: Pancreatic ductal adenocarcinoma; PROMPTs: Promoter upstream transcripts; PVT1: Plasmacytoma variant translocation 1; RCC: Renal Cell Carcinoma; RNP: Ribonucleic protein; SNCG: Synuclein gamma; TNBC: Triple-negative breast cancer; UCA1: Urothelial cancer associated 1 UPR: Unfolded protein response; UTR: Untranslated region; VHL: von Hippel-Lindau protein

\section{Acknowledgements}

We are immensely grateful to all the members of Kung labs for their valuable suggestions, feedback and contribution to our studies.

\section{Funding}

This work was part financed by US National Institutes of Health (CA114575, CA165263), National Health Research Institutes of Taiwan (NHRI03A1-MGPP18-014, NHRI04A1-MGPP15-014, NHRI05A1-MGPP15-014), Ministry of Health and Welfare of Taiwan (MOHW104-TDU-M-212-13,304) and Ministry of Science and Technology of Taiwan (MOST102-2320-B-400-018-MY3, MOST104-2321-B-400-009) to HJK. This work is also supported by National Science Council of Taiwan (NSC101-2917-I564-022, NSC102-2811-B-038-008, NSC102-2321-B-038-006) and Health and welfare surcharge of tobacco products (MOHW106-TDU-B-212-144001) to JWS.

Availability of data and materials Not Applicable.

\section{Authors' contributions}

JWS and HJK wrote the manuscript. Both authors read and approved the final manuscript.

\section{Ethics approval and consent to participate}

Not applicable.

\section{Consent for publication}

Not Applicable.

\section{Competing interests}

The authors declare that they have no competing interests.

\section{Publisher's Note}

Springer Nature remains neutral with regard to jurisdictional claims in published maps and institutional affiliations.

\section{Author details}

${ }^{1}$ Ph.D. Program for Cancer Biology and Drug Discovery, College of Medical Science and Technology, Taipei Medical University, Taipei 110, Taiwan.

${ }^{2}$ Research Center of Cancer Translational Medicine, Taipei Medical University, Taipei 110, Taiwan. ${ }^{3}$ Ph.D. Program for Translational Medicine, College of Medical Science and Technology, Taipei Medical University, Taipei 110, Taiwan. ${ }^{4}$ Department of Biochemistry and Molecular Medicine,

Comprehensive Cancer Center, University of California at Davis, Sacramento, CA 95817, USA. ${ }^{5}$ Institute of Molecular and Genomic Medicine, National Health Research Institutes, Zhunan, Miaoli County 350, Taiwan.

Received: 2 June 2017 Accepted: 25 July 2017

Published online: 08 August 2017

\section{References}

1. Semenza GL. Oxygen homeostasis. Wiley interdisciplinary reviews. Syst Biol Med. 2010;2:336-61

2. Liu Q, Liu L, Zhao Y, Zhang J, Wang D, Chen J, et al. Hypoxia induces genomic DNA demethylation through the activation of HIF-1alpha and transcriptional upregulation of MAT2A in hepatoma cells. Mol Cancer Ther. 2011;10:1113-23. 
3. Jackson AL, Zhou B, Kim WY. HIF, hypoxia and the role of angiogenesis in non-small cell lung cancer. Expert Opin Ther Targets. 2010;14:1047-57.

4. Harrison LR, Micha D, Brandenburg M, Simpson KL, Morrow CJ, Denneny O, et al. Hypoxic human cancer cells are sensitized to $\mathrm{BH}-3$ mimetic-induced apoptosis via downregulation of the $\mathrm{BCl}-2$ protein $\mathrm{MCl}-1$. J Clin Invest. 2011;121:1075-87.

5. Iyer NV, Kotch LE, Agani F, Leung SW, Laughner E, Wenger RH, et al. Cellular and developmental control of $\mathrm{O} 2$ homeostasis by hypoxia-inducible factor 1 alpha. Genes Dev. 1998;12:149-62.

6. Wang $G L$, Jiang BH, Rue EA, Semenza GL. Hypoxia-inducible factor 1 is a basic-helix-loop-helix-PAS heterodimer regulated by cellular $\mathrm{O} 2$ tension. Proc Natl Acad Sci U S A. 1995;92:5510-4.

7. Keith B, Simon MC. Hypoxia-inducible factors, stem cells, and cancer. Cell. 2007;129:465-72.

8. Kelly BD, Hackett SF, Hirota K, Oshima Y, Cai Z, Berg-Dixon S, et al. Cell type-specific regulation of angiogenic growth factor gene expression and induction of angiogenesis in nonischemic tissue by a constitutively active form of hypoxia-inducible factor 1. Circ Res. 2003;93:1074-81.

9. Semenza GL. Defining the role of hypoxia-inducible factor 1 in cancer biology and therapeutics. Oncogene. 2010;29:625-34.

10. Kaelin WG Jr, Ratcliffe PJ. Oxygen sensing by metazoans: the central role of the HIF hydroxylase pathway. Mol Cell. 2008;30:393-402.

11. Semenza GL. Oxygen sensing, hypoxia-inducible factors, and disease pathophysiology. Annu Rev Pathol. 2014;9:47-71

12. Djebali S, Davis CA, Merkel A, Dobin A, Lassmann T, Mortazavi A, et al. Landscape of transcription in human cells. Nature. 2012;489:101-8.

13. Consortium EP, Birney E, Stamatoyannopoulos JA, Dutta A, Guigo R, Gingeras TR, et al. Identification and analysis of functional elements in $1 \%$ of the human genome by the ENCODE pilot project. Nature. 2007;447:799-816.

14. Rinn JL, Chang HY. Genome regulation by long noncoding RNAs. Annu Rev Biochem. 2012;81:145-66.

15. Kapranov P, Cheng J, Dike S, Nix DA, Duttagupta R, Willingham AT, et al. RNA maps reveal new RNA classes and a possible function for pervasive transcription. Science. 2007;316:1484-8

16. Ravasi T, Suzuki H, Pang KC, Katayama S, Furuno M, Okunishi R, et al. Experimental validation of the regulated expression of large numbers of non-coding RNAs from the mouse genome. Genome Res. 2006;16:11-9.

17. Kung JT, Colognori D, Lee JT. Long noncoding RNAs: past, present, and future. Genetics. 2013;193:651-69.

18. Batista PJ, Chang HY. Long noncoding RNAs: cellular address codes in development and disease. Cell. 2013;152:1298-307.

19. Aken BL, Achuthan P, Akanni W, Amode MR, Bernsdorff F, Bhai J, et al. Ensembl 2017. Nucleic Acids Res. 2017:45:D635-D42.

20. Harrow J, Frankish A, Gonzalez JM, Tapanari E, Diekhans M, Kokocinski F, et al. GENCODE: the reference human genome annotation for the ENCODE project. Genome Res. 2012;22:1760-74.

21. Baker M. Long noncoding RNAs: the search for function. Nat Methods. 2011;8:379-83.

22. Moran VA, Perera RJ, Khalil AM. Emerging functional and mechanistic paradigms of mammalian long non-coding RNAs. Nucleic Acids Res. 2012:40:6391-400

23. Wilusz JE, Sunwoo H, Spector DL. Long noncoding RNAs: functional surprises from the RNA world. Genes Dev. 2009;23:1494-504.

24. Lee JT. Epigenetic regulation by long noncoding RNAs. Science. 2012;338:1435-9.

25. Yang L, Froberg JE, Lee JT. Long noncoding RNAs: fresh perspectives into the RNA world. Trends Biochem Sci. 2014;39:35-43.

26. Geisler S, Coller J. RNA in unexpected places: long non-coding RNA functions in diverse cellular contexts. Nature reviews. Mol Cell Biol. 2013;14:699-712.

27. Bonasio R, Shiekhattar R. Regulation of transcription by long noncoding RNAs. Annu Rev Genet. 2014;48:433-55.

28. Wang KC, Chang HY. Molecular mechanisms of long noncoding RNAs. Mol Cell. 2011:43:904-14.

29. Bohmdorfer $\mathrm{G}$, Wierzbicki AT. Control of chromatin structure by long noncoding RNA. Trends Cell Biol. 2015;25:623-32.

30. Schmitt AM, Chang HY. Long noncoding RNAs in cancer pathways. Cancer Cell. 2016:29:452-63.

31. Gong C, Maquat LE. IncRNAs transactivate STAU1-mediated mRNA decay by duplexing with 3' UTRs via Alu elements. Nature. 2011;470:284-8.

32. Clemson CM, Hutchinson JN, Sara SA, Ensminger AW, Fox AH, Chess A, et al. An architectural role for a nuclear noncoding RNA: NEAT1 RNA is essential for the structure of paraspeckles. Mol Cell. 2009;33:717-26.
33. Shevtsov SP, Dundr M. Nucleation of nuclear bodies by RNA. Nat Cell Biol. 2011;13:167-73.

34. Hung T, Chang HY. Long noncoding RNA in genome regulation: prospects and mechanisms. RNA Biol. 2010;7:582-5.

35. Dinger ME, Amaral PP, Mercer TR, Pang KC, Bruce SJ, Gardiner BB, et al. Long noncoding RNAs in mouse embryonic stem cell pluripotency and differentiation. Genome Res. 2008;18:1433-45.

36. Mercer TR, Dinger ME, Sunkin SM, Mehler MF, Mattick JS. Specific expression of long noncoding RNAs in the mouse brain. Proc Natl Acad Sci U S A. 2008;105:716-21.

37. Wapinski $\mathrm{O}$, Chang HY. Long noncoding RNAs and human disease. Trends Cell Biol. 2011;21:354-61.

38. Gibb EA, Brown CJ, Lam WL. The functional role of long non-coding RNA in human carcinomas. Mol Cancer. 2011;10:38.

39. Gutschner T, Diederichs S. The hallmarks of cancer: a long non-coding RNA point of view. RNA Biol. 2012;9:703-19.

40. Spizzo R, Almeida MI, Colombatti A, Calin GA. Long non-coding RNAs and cancer: a new frontier of translational research? Oncogene. 2012;31:4577-87.

41. Huarte M. The emerging role of IncRNAs in cancer. Nat Med. 2015;21:1253-61.

42. Qiu MT, Hu JW, Yin R, Xu L. Long noncoding RNA: an emerging paradigm of cancer research. Tumour Biol. 2013;34:613-20.

43. Chang YN, Zhang K, Hu ZM, Qi HX, Shi ZM, Han XH, et al. Hypoxia-regulated IncRNAs in cancer. Gene. 2016:575:1-8.

44. Choudhry H, Harris AL, Mclntyre A. The tumour hypoxia induced non-coding transcriptome. Mol Asp Med. 2016:47-48:35-53.

45. Dong J, Xu J, Wang $X$, Jin B. Influence of the interaction between long noncoding RNAs and hypoxia on tumorigenesis. Tumour Biol. 2016;37:1379-85.

46. Lorenzen JM, Thum T. Long noncoding RNAs in kidney and cardiovascular diseases. Nat Rev Nephrol. 2016;12:360-73.

47. El Azzouzi H, Doevendans PA, Sluijter JP. Long non-coding RNAs in heart failure: an obvious Inc. Ann Transl Med. 2016;4:182.

48. Kaur P, Liu F, Tan JR, Lim KY, Sepramaniam S, Karolina DS, et al. Non-coding RNAs as potential Neuroprotectants against ischemic brain injury. Brain Sci. 2013;3:360-95.

49. Takahashi K, Yan IK, Haga H, Patel T. Modulation of hypoxia-signaling pathways by extracellular linc-RoR. J Cell Sci. 2014;127:1585-94.

50. Wang Y, Liu X, Zhang H, Sun L, Zhou Y, Jin H, et al. Hypoxia-inducible IncRNA-AK058003 promotes gastric cancer metastasis by targeting gammasynuclein. Neoplasia. 2014;16:1094-106.

51. Choudhry H, Schodel J, Oikonomopoulos S, Camps C, Grampp S, Harris AL, et al. Extensive regulation of the non-coding transcriptome by hypoxia: role of HIF in releasing paused RNApol2. EMBO Rep. 2014;15:70-6.

52. Fish JE, Matouk CC, Yeboah E, Bevan SC, Khan M, Patil K, et al. Hypoxiainducible expression of a natural cis-antisense transcript inhibits endothelial nitric-oxide synthase. J Biol Chem. 2007;282:15652-66.

53. Zhou C, Ye L, Jiang C, Bai J, Chi Y, Zhang H. Long noncoding RNA HOTAIR, a hypoxia-inducible factor-1alpha activated driver of malignancy, enhances hypoxic cancer cell proliferation, migration, and invasion in non-small cell lung cancer. Tumour Biol. 2015;36:9179-88.

54. Matouk IJ, DeGroot N, Mezan S, Ayesh S, Abu-lail R, Hochberg A, et al. The H19 non-coding RNA is essential for human tumor growth. PLoS One. 2007:2:e845.

55. Xue M, Li X, Li Z, Chen W. Urothelial carcinoma associated 1 is a hypoxiainducible factor-1alpha-targeted long noncoding RNA that enhances hypoxic bladder cancer cell proliferation, migration, and invasion. Tumour Biol. 2014;35:6901-12.

56. Li X, Deng SJ, Zhu S, Jin Y, Cui SP, Chen JY, et al. Hypoxia-induced IncRNANUTF2P3-001 contributes to tumorigenesis of pancreatic cancer by derepressing the miR-3923/KRAS pathway. Oncotarget. 2016;7:6000-14.

57. Gomez-Maldonado L, Tiana M, Roche O, Prado-Cabrero A, Jensen L, Fernandez-Barral A, et al. EFNA3 long noncoding RNAs induced by hypoxia promote metastatic dissemination. Oncogene. 2015;34:2609-20.

58. Ferdin J, Nishida N, Wu X, Nicoloso MS, Shah MY, Devlin C, et al. HINCUTs in cancer: hypoxia-induced noncoding ultraconserved transcripts. Cell Death Differ. 2013;20:1675-87.

59. Wei X, Wang C, Ma C, Sun W, Li H, Cai Z. Long noncoding RNA ANRIL is activated by hypoxia-inducible factor-1alpha and promotes osteosarcoma cell invasion and suppresses cell apoptosis upon hypoxia. Cancer Cell Int. 2016;16:73.

60. Liu L, Zhao X, Zou H, Bai R, Yang K, Tian Z. Hypoxia promotes gastric cancer malignancy partly through the HIF-1alpha dependent transcriptional activation of the long non-coding RNA GAPLINC. Front Physiol. 2016;7:420. 
61. Yang F, Zhang $H$, Mei $Y$, Wu M. Reciprocal regulation of HIF-1alpha and lincRNA-p21 modulates the Warburg effect. Mol Cell. 2014;53:88-100.

62. Thrash-Bingham CA, Tartof KD. aHIF: a natural antisense transcript overexpressed in human renal cancer and during hypoxia. J Natl Cancer Inst. 1999;91:143-51.

63. McCarty G, Loeb DM. Hypoxia-sensitive epigenetic regulation of an antisense-oriented IncRNA controls WT1 expression in myeloid leukemia cells. PLoS One. 2015;10:e0119837.

64. Shih JW, Chiang WF, Wu ATH, Wu MH, Wang LY, Yu YL, et al. Long noncoding RNA LncHIFCAR/MIR31HG is a HIF-1a co-activator driving oral cancer progression. Nat Commun. 2017; doi:10.1038/ncomms15874.

65. Wiedmeier JE, Ohlrich A, Chu A, Rountree MR, Turker MS. Induction of the long noncoding RNA NBR2 from the bidirectional BRCA1 promoter under hypoxic conditions. Mutat Res. 2017;796:13-9.

66. Yang Z, Wang R, Zhang T, Dong X. Hypoxia/IncRNA-AK123072/EGFR pathway induced metastasis and invasion in gastric cancer. Int J Clin Exp Med. 2015:8:19954-68.

67. Iden M, Fye S, Li K, Chowdhury T, Ramchandran R, Rader JS. The IncRNA PVT1 contributes to the cervical cancer phenotype and associates with poor patient prognosis. PLoS One. 2016;11:e0156274.

68. Yang F, Huo XS, Yuan SX, Zhang L, Zhou WP, Wang F, et al. Repression of the long noncoding RNA-LET by histone deacetylase 3 contributes to hypoxia-mediated metastasis. Mol Cell. 2013;49:1083-96.

69. Sun YW, Chen YF, Li J, Huo YM, Liu DJ, Hua R, et al. A novel long non-coding RNA ENST00000480739 suppresses tumour cell invasion by regulating OS-9 and HIF-1alpha in pancreatic ductal adenocarcinoma. Br J Cancer. 2014;111:2131-41.

70. Zhai W, Sun Y, Jiang M, Wang M, Gasiewicz TA, Zheng J, et al. Differential regulation of LnCRNA-SARCC suppresses VHL-mutant RCC cell proliferation yet promotes $\mathrm{VHL}$-normal RCC cell proliferation via modulating androgen receptor/HIF-2alpha/C-MYC axis under hypoxia. Oncogene. 2016;35:4866-80.

71. Matouk IJ, Mezan S, Mizrahi A, Ohana P, Abu-Lail R, Fellig Y, et al. The oncofetal H19 RNA connection: hypoxia, p53 and cancer. Biochim Biophys Acta. 1803;2010:443-51.

72. Wu W, Hu Q, Nie E, Yu T, Wu Y, Zhi T, et al. Hypoxia induces H19 expression through direct and indirect Hif-1alpha activity, promoting oncogenic effects in glioblastoma. Sci Rep. 2017;7:45029.

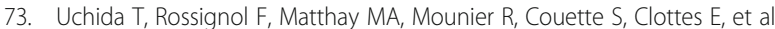
Prolonged hypoxia differentially regulates hypoxia-inducible factor (HIF)1alpha and HIF-2alpha expression in lung epithelial cells: implication of natural antisense HIF-1alpha. J Biol Chem. 2004;279:14871-8.

74. Lelli A, Nolan KA, Santambrogio S, Goncalves AF, Schonenberger MJ, Guinot A, et al. Induction of long noncoding RNA MALAT1 in hypoxic mice. Hypoxia (Auckl). 2015;3:45-52.

75. Quinn JJ, Chang HY. Unique features of long non-coding RNA biogenesis and function. Nat Rev Genet. 2016;17:47-62.

76. Moorwood K, Charles AK, Salpekar A, Wallace Jl, Brown KW, Malik K. Antisense WT1 transcription parallels sense mRNA and protein expression in fetal kidney and can elevate protein levels in vitro. J Pathol. 1998;185:352-9.

77. Baek JH, Mahon PC, Oh J, Kelly B, Krishnamachary B, Pearson M, et al. OS-9 interacts with hypoxia-inducible factor 1alpha and prolyl hydroxylases to promote oxygen-dependent degradation of HIF-1alpha. Mol Cell. 2005;17:503-12.

78. Zhu Z, Gao X, He Y, Zhao H, Yu Q, Jiang D, et al. An insertion/deletion polymorphism within RERT-IncRNA modulates hepatocellular carcinoma risk. Cancer Res. 2012;72:6163-72.

79. Wang Y, Yao J, Meng H, Yu Z, Wang Z, Yuan X, et al. A novel long noncoding RNA, hypoxia-inducible factor-2alpha promoter upstream transcript, functions as an inhibitor of osteosarcoma stem cells in vitro. Mol Med Rep. 2015;11:2534-40.

80. Ma MZ, Kong X, Weng MZ, Zhang MD, Qin YY, Gong W, et al. Long noncoding RNA-LET is a positive prognostic factor and exhibits tumorsuppressive activity in gallbladder cancer. Mol Carcinog. 2015;54:1397-406.

81. Kuwano Y, Pullmann R Jr, Marasa BS, Abdelmohsen K, Lee EK, Yang X, et al. NF90 selectively represses the translation of target mRNAs bearing an AUrich signature motif. Nucleic Acids Res. 2010;38:225-38.

82. Rossignol F, Vache C, Clottes E. Natural antisense transcripts of hypoxiainducible factor 1alpha are detected in different normal and tumour human tissues. Gene. 2002;299:135-40.

83. Bertozzi D, lurlaro R, Sordet O, Marinello J, Zaffaroni N, Capranico G. Characterization of novel antisense HIF-1alpha transcripts in human cancers. Cell Cycle. 2011;10:3189-97.
84. Chen WM, Huang MD, Kong R, Xu TP, Zhang EB, Xia R, et al. Antisense long noncoding RNA HIF1A-AS2 is Upregulated in gastric cancer and associated with poor prognosis. Dig Dis Sci. 2015;60:1655-62.

85. Mineo M, Ricklefs F, Rooj AK, Lyons SM, Ivanov P, Ansari Kl, et al. The long non-coding RNA HIF1A-AS2 facilitates the maintenance of Mesenchymal Glioblastoma stem-like cells in hypoxic niches. Cell Rep. 2016;15:2500-9.

86. Xu Q, Liu LZ, Qian X, Chen Q, Jiang Y, Li D, et al. MiR-145 directly targets p70S6K1 in cancer cells to inhibit tumor growth and angiogenesis. Nucleic Acids Res. 2012:40:761-74.

87. Colombo T, Farina L, Macino G, Paci P. PVT1: a rising star among oncogenic long noncoding RNAs. Biomed Res Int. 2015;2015:304208.

88. Cui M, You L, Ren X, Zhao W, Liao Q, Zhao Y. Long non-coding RNA PVT1 and cancer. Biochem Biophys Res Commun. 2016;471:10-4.

89. Huang T, Liu HW, Chen JQ, Wang SH, Hao LQ, Liu M, et al. The long noncoding RNA PVT1 functions as a competing endogenous RNA by sponging miR-186 in gastric cancer. Biomed Pharmacother. 2017;88:302-8.

90. Hu Y, Wang J, Qian J, Kong X, Tang J, Wang Y, et al. Long noncoding RNA GAPLINC regulates CD44-dependent cell invasiveness and associates with poor prognosis of gastric cancer. Cancer Res. 2014;74:6890-902.

91. Huang X, Ding L, Bennewith KL, Tong RT, Welford SM, Ang KK, et al. Hypoxia-inducible mir-210 regulates normoxic gene expression involved in tumor initiation. Mol Cell. 2009;35:856-67.

92. Fasanaro P, D'Alessandra Y, Di Stefano V, Melchionna R, Romani S, Pompilio G, et al. MicroRNA-210 modulates endothelial cell response to hypoxia and inhibits the receptor tyrosine kinase ligand Ephrin-A3. J Biol Chem. 2008;283:15878-83.

93. Wang Z, Yin B, Wang B, Ma Z, Liu W, Lv G. MicroRNA-210 promotes proliferation and invasion of peripheral nerve sheath tumor cells targeting EFNA3. Oncol Res. 2013;21:145-54.

94. Raveh E, Matouk IJ, Gilon M, Hochberg A. The H19 long non-coding RNA in cancer initiation, progression and metastasis - a proposed unifying theory. Mol Cancer. 2015;14:184.

95. Huarte M, Guttman M, Feldser D, Garber M, Koziol MJ, Kenzelmann-Broz D, et al. A large intergenic noncoding RNA induced by p53 mediates global gene repression in the p53 response. Cell. 2010;142:409-19.

96. Lin A, Li C, Xing Z, Hu Q, Liang K, Han L, et al. The LINK-A IncRNA activates normoxic HIF1alpha signalling in triple-negative breast cancer. Nat Cell Biol. 2016;18:213-24.

97. Ip JY, Nakagawa S. Long non-coding RNAs in nuclear bodies. Develop Growth Differ. 2012;54:44-54.

98. Schmidt LH, Spieker T, Koschmieder S, Schaffers S, Humberg J, Jungen D, et al. The long noncoding MALAT-1 RNA indicates a poor prognosis in non-small cell lung cancer and induces migration and tumor growth. J Thorac Oncol. 2011;6:1984-92.

99. Michalik KM, You X, Manavski Y, Doddaballapur A, Zornig M, Braun T, et al. Long noncoding RNA MALAT1 regulates endothelial cell function and vessel growth. Circ Res. 2014;114:1389-97.

100. Gutschner T, Hammerle M, Diederichs S. MALAT1- a paradigm for long noncoding RNA function in cancer. J Mol Med (Berl). 2013;91:791-801.

101. Hutchinson JN, Ensminger AW, Clemson CM, Lynch CR, Lawrence JB, Chess A. A screen for nuclear transcripts identifies two linked noncoding RNAs associated with SC35 splicing domains. BMC Genomics. 2007:8:39.

102. Tripathi V, Ellis JD, Shen Z, Song DY, Pan Q, Watt AT, et al. The nuclearretained noncoding RNA MALAT1 regulates alternative splicing by modulating SR splicing factor phosphorylation. Mol Cell. 2010;39:925-38.

103. Luo F, Liu X, Ling M, Lu L, Shi L, Lu X, et al. The IncRNA MALAT1, acting through HIF-1alpha stabilization, enhances arsenite-induced glycolysis in human hepatic L-02 cells. Biochim Biophys Acta. 1862;2016:1685-95.

104. Choudhry H, Mole DR. Hypoxic regulation of the noncoding genome and NEAT1. Brief Funct Genomics. 2016;15:174-85.

105. Choudhry H, Albukhari A, Morotti M, Haider S, Moralli D, Smythies J, et al. Tumor hypoxia induces nuclear paraspeckle formation through HIF-2alpha dependent transcriptional activation of NEAT1 leading to cancer cell survival. Oncogene. 2015;34:4482-90.

106. Ben-Zvi M, Amariglio N, Paret G, Nevo-Caspi Y. F11R expression upon hypoxia is regulated by RNA editing. PLoS One. 2013;8:e77702.

107. Chakravarty D, Sboner A, Nair SS, Giannopoulou E, Li R, Hennig S, et al. The oestrogen receptor alpha-regulated IncRNA NEAT1 is a critical modulator of prostate cancer. Nat Commun. 2014;5:5383.

108. Ortiz-Barahona A, Villar D, Pescador N, Amigo J, del Peso L. Genome-wide identification of hypoxia-inducible factor binding sites and target genes by 
a probabilistic model integrating transcription-profiling data and in silico binding site prediction. Nucleic Acids Res. 2010;38:2332-45.

109. Weigand JE, Boeckel JN, Gellert P, Dimmeler S. Hypoxia-induced alternative splicing in endothelial cells. PLoS One. 2012;7:e42697.

110. Nevo-Caspi Y, Amariglio N, Rechavi G, Paret G. A-to-I RNA editing is induced upon hypoxia. Shock. 2011;35:585-9.

111. Shih JW, Lee YH. Human DExD/H RNA helicases: emerging roles in stress survival regulation. Clin Chim Acta. 2014;436:45-58.

112. Turner M, Galloway A, Vigorito E. Noncoding RNA and its associated proteins as regulatory elements of the immune system. Nat Immunol. 2014;15:484-91.

113. Denzler R, Agarwal V, Stefano J, Bartel DP, Stoffel M. Assessing the ceRNA hypothesis with quantitative measurements of miRNA and target abundance. Mol Cell. 2014;54:766-76.

114. Span PN, Bussink J. Biology of hypoxia. Semin Nucl Med. 2015:45:101-9.

115. Hansen AE, Kristensen AT, Law I, Jorgensen JT, Engelholm SA. Hypoxiainducible factors-regulation, role and comparative aspects in tumourigenesis. Vet Comp Oncol. 2011;9:16-37.

116. Yao J, Li J, Geng P, Li Y, Chen H, Zhu Y. Knockdown of a HIF-2alpha promoter upstream long noncoding RNA impairs colorectal cancer stem cell properties in vitro through HIF-2alpha downregulation. Onco Targets Ther. 2015:8:3467-74.

117. Van Roosbroeck K, Pollet J, Calin GA. miRNAs and long noncoding RNAs as biomarkers in human diseases. Expert Rev Mol Diagn. 2013;13:183-204.

118. Wan Y, Qu K, Zhang QC, Flynn RA, Manor O, Ouyang Z, et al. Landscape and variation of RNA secondary structure across the human transcriptome. Nature. 2014;505:706-9.

119. Qi P, Du X. The long non-coding RNAs, a new cancer diagnostic and therapeutic gold mine. Mod Pathol. 2013;26:155-65.

120. $\mathrm{Li} \mathrm{CH}$, Chen Y. Targeting long non-coding RNAs in cancers: progress and prospects. Int J Biochem Cell Biol. 2013;45:1895-910.

121. Kole R, Krainer AR, Altman S. RNA therapeutics: beyond RNA interference and antisense oligonucleotides. Nat Rev Drug Discov. 2012;11:125-40.

122. Voellenkle C, Garcia-Manteiga JM, Pedrotti S, Perfetti A, De Toma I, Da Silva D, et al. Implication of long noncoding RNAs in the endothelial cell response to hypoxia revealed by RNA-sequencing. Sci Rep. 2016;6:24141.

123. Wang F, Li X, Xie X, Zhao L, Chen W. UCA1, a non-protein-coding RNA up-regulated in bladder carcinoma and embryo, influencing cell growth and promoting invasion. FEBS Lett. 2008:582:1919-27.

124. Luo F, Sun B, Li H, Xu Y, Liu Y, Liu X, et al. A MALAT1/HIF-2alpha feedback loop contributes to arsenite carcinogenesis. Oncotarget. 2016;7:5769-87.

125. Dallosso AR, Hancock AL, Malik S, Salpekar A, King-Underwood L, PritchardJones K, et al. Alternately spliced WT1 antisense transcripts interact with WT1 sense RNA and show epigenetic and splicing defects in cancer. RNA. 2007;13:2287-99.

126. Tee AE, Liu B, Song R, Li J, Pasquier E, Cheung BB, et al. The long noncoding RNA MALAT1 promotes tumor-driven angiogenesis by upregulating pro-angiogenic gene expression. Oncotarget. 2016;7:8663-75.

127. Liu XH, Liu ZL, Sun M, Liu J, Wang ZX, De W. The long non-coding RNA HOTAIR indicates a poor prognosis and promotes metastasis in non-small cell lung cancer. BMC Cancer. 2013;13:464.

\section{Submit your next manuscript to BioMed Central and we will help you at every step:}

- We accept pre-submission inquiries

- Our selector tool helps you to find the most relevant journal

- We provide round the clock customer support

- Convenient online submission

- Thorough peer review

- Inclusion in PubMed and all major indexing services

- Maximum visibility for your research

Submit your manuscript at www.biomedcentral.com/submit

) Biomed Central 